\title{
Aerosol optical depth measurements by airborne sun photometer in SOLVE II: Comparisons to SAGE III, POAM III and airborne spectrometer measurements
}

\author{
P. Russell ${ }^{1}$, J. Livingston ${ }^{2}$, B. Schmid ${ }^{3}$, J. Eilers ${ }^{1}$, R. Kolyer ${ }^{1}$, J. Redemann ${ }^{3}$, S. Ramirez ${ }^{3}$, J.-H. Yee $^{4}$, W. Swartz ${ }^{4}$, \\ R. Shetter ${ }^{5}$, C. Trepte ${ }^{6}$, A. Risley Jr. ${ }^{7}$, B. Wenny ${ }^{7}$, J. Zawodny ${ }^{6}$, W. Chu ${ }^{6}$, M. Pitts ${ }^{6}$, J. Lumpe ${ }^{8}$, M. Fromm ${ }^{9}$, \\ C. Randall ${ }^{10}$, K. Hoppel ${ }^{9}$, and R. Bevilacqua ${ }^{9}$ \\ ${ }^{1}$ NASA Ames Research Center, MS 245-5, Moffett Field, CA 94035-1000, USA \\ ${ }^{2}$ SRI International, Menlo Park, CA 94025, USA \\ ${ }^{3}$ Bay Area Environmental Research Institute, Sonoma, CA 95476, USA \\ ${ }^{4}$ Applied Physics Laboratory, Johns Hopkins University, Laurel, MD 20723-6099, USA \\ ${ }^{5}$ National Center for Atmospheric Research, Boulder, CO 80307-3000, USA \\ ${ }^{6}$ NASA Langley Research Center, Hampton, VA 23681-2199, USA \\ ${ }^{7}$ SAIC, NASA Langley Research Center, Hampton, VA 23681-0001, USA \\ ${ }^{8}$ Computational Physics, Inc., Springfield, VA 22151, USA \\ ${ }^{9}$ Naval Research Laboratory, Washington, DC 20375-5351, USA \\ ${ }^{10}$ Laboratory for Atmospheric and Space Physics, University of Colorado, Boulder, CO 80309-0392, USA
}

Received: 8 October 2004 - Published in Atmos. Chem. Phys. Discuss.: 5 November 2004

Revised: 25 February 2005 - Accepted: 1 April 2005 - Published: 1 June 2005

\begin{abstract}
The 14-channel NASA Ames Airborne Tracking Sunphotometer (AATS-14) measured solar- beam transmission on the NASA DC-8 during the second SAGE III Ozone Loss and Validation Experiment (SOLVE II). This paper presents AATS-14 results for multiwavelength aerosol optical depth $(A O D)$, including comparisons to results from two satellite sensors and another DC-8 instrument, namely the Stratospheric Aerosol and Gas Experiment III (SAGE III), the Polar Ozone and Aerosol Measurement III (POAM III) and the Direct-beam Irradiance Airborne Spectrometer (DIAS). AATS-14 provides aerosol results at 13 wavelengths $\lambda$ spanning the range of SAGE III and POAM III aerosol wavelengths. Because most AATS measurements were made at solar zenith angles $(S Z A)$ near $90^{\circ}$, retrieved $A O D$ s are strongly affected by uncertainties in the relative optical airmass of the aerosols and other constituents along the line of sight (LOS) between instrument and sun. To reduce dependence of the AATS-satellite comparisons on airmass, we perform the comparisons in LOS transmission and LOS optical thickness (OT) as well as in vertical OT (i.e., optical depth, $O D)$. We also use a new airmass algorithm that validates the algorithm we previously used to within $2 \%$ for $S Z A<90^{\circ}$, and in addition provides results for $S Z A \geq 90^{\circ}$.
\end{abstract}

For 6 DC-8 flights, 19 January-2 February 2003, AATS and DIAS results for LOS aerosol OT at $\lambda=400 \mathrm{~nm}$ agree to $\leq 12 \%$ of the AATS value. Mean and root-mean-square (RMS) differences, (DIAS-AATS)/AATS, are $-2.3 \%$ and $7.7 \%$, respectively. For DC-8 altitudes, AATS-satellite comparisons are possible only for $\lambda>440 \mathrm{~nm}$, because of signal depletion for shorter $\lambda$ on the satellite full-limb LOS. For the 4 AATS-SAGE and 4 AATS-POAM near-coincidences conducted 19-31 January 2003, AATS-satellite $A O D$ differences were $\leq 0.0041$ for all $\lambda>440 \mathrm{~nm}$. RMS differences were $\leq 0.0022$ for SAGE-AATS and $\leq 0.0026$ for POAM-AATS. RMS relative differences in $A O D$ ([SAGE-AATS]/AATS) were $\leq 33 \%$ for $\lambda<\sim 755 \mathrm{~nm}$, but grew to $59 \%$ for $1020 \mathrm{~nm}$ and $66 \%$ at $1545 \mathrm{~nm}$. For $\lambda>\sim 755 \mathrm{~nm}$, AATS-POAM differences were less than AATS-SAGE differences, and RMS relative differences in $A O D$ ([AATS-POAM]/AATS) were $\leq 31 \%$ for all $\lambda$ between 440 and $1020 \mathrm{~nm}$. Unexplained differences that remain are associated with transmission differences, rather than differences in gas subtraction or conversion from LOS to vertical quantities. The very small stratospheric $A O D$ values that occurred during SOLVE II added to the challenge of the comparisons, but do not explain all the differences.

Correspondence to: P. Russell

(philip.b.russell@nasa.gov)

(C) 2005 Author(s). This work is licensed under a Creative Commons License. 

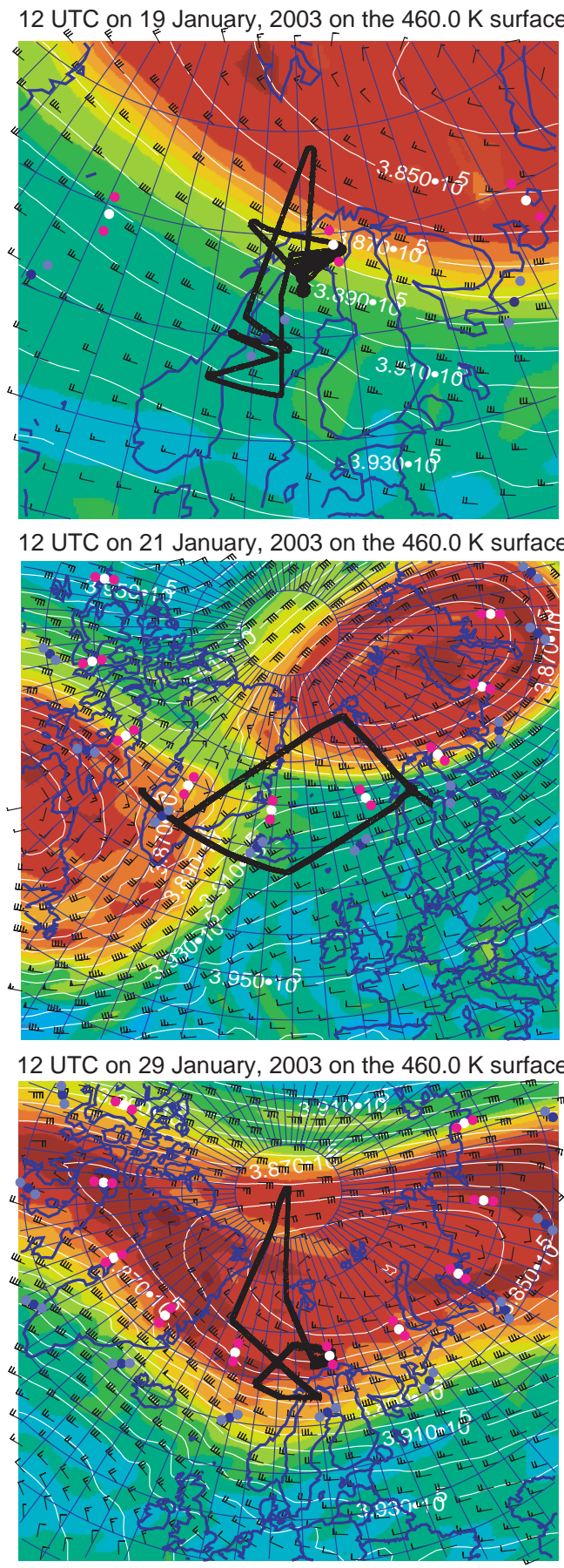

NMC, Grid: GG1X1

Seq: E01, Spec: SSIAVN

MPV (PVU)

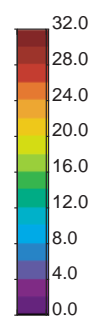

WND2 (m/s)

$\operatorname{MNST}\left(\mathrm{J} / \mathrm{kg}^{\wedge}-1\right)$
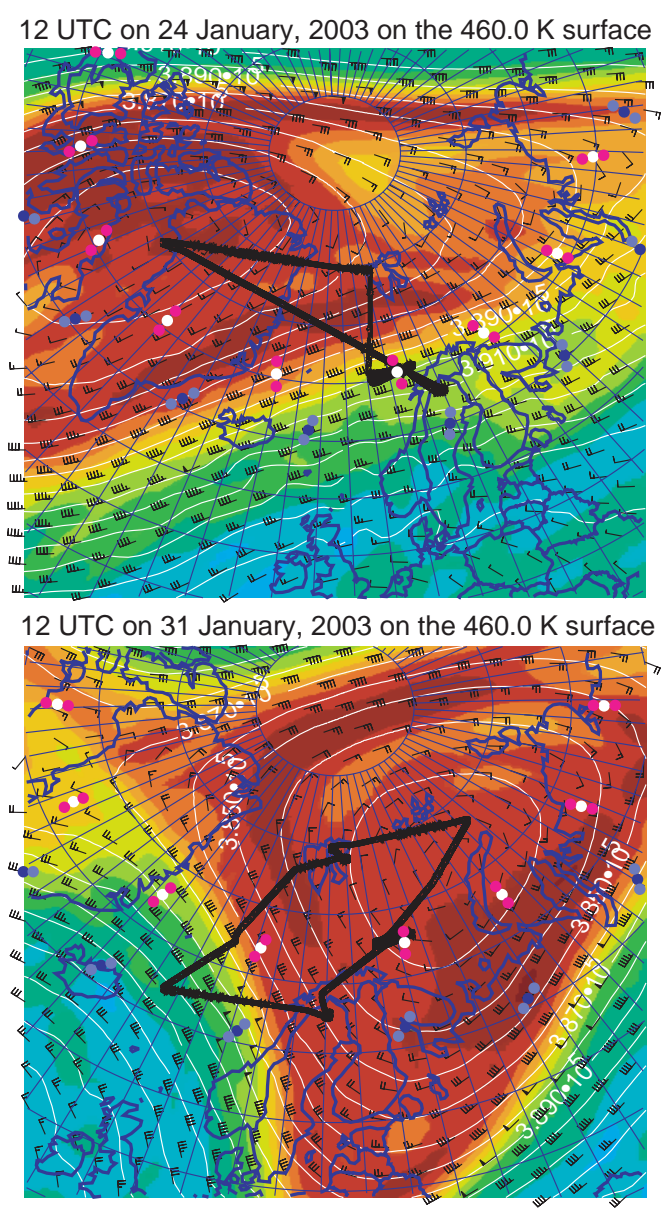

Fig. 1. DC-8 flight tracks (black) superimposed on $12 \mathrm{Z}$ analysis maps of modified potential vorticity (MPV) for the $460 \mathrm{~K}$ isentropic surface. White and blue points mark occultations by SAGE III and POAM III, respectively. Maps were produced by L. Lait, M. Schoeberl, and P. Newman.

\section{Introduction}

The 14-channel NASA Ames Airborne Tracking Sunphotometer (AATS-14) measured solar- beam transmission on the NASA DC-8 during the second SAGE III Ozone Loss and Validation Experiment (SOLVE II). Flights were made out of Kiruna, Sweden, and Dryden Flight Research Facility in Southern California, USA. Livingston et al. (2005) describe the AATS-14 instrument, measurement procedures, and results for ozone. This paper presents AATS-14 results for multiwavelength aerosol optical depth $(A O D)$, including its spatial structure and its relationship to results from two 
satellite sensors and another DC-8 instrument. These are the Stratospheric Aerosol and Gas Experiment III (SAGE III), the Polar Ozone and Aerosol Measurement III (POAM III) and the Direct beam Irradiance Airborne Spectrometer (DIAS).

AATS-14 provides aerosol results at 13 wavelengths $\lambda$ between 354 and $2139 \mathrm{~nm}$, spanning the full range of aerosol wavelengths for SAGE III (384-1545 nm) and POAM III (353-1018 nm). In this paper we show AATS results only for wavelengths $354-1558 \mathrm{~nm}$, because no correlative measurements are available to compare to the AATS results at $2139 \mathrm{~nm}$. The AATS-14 channels used in this paper have full width at half maximum (FWHM) of 2.0 to $5.6 \mathrm{~nm}$, with most channel FWHMs $\sim 5 \mathrm{~nm}$. Because most AATS measurements in SOLVE II were made at solar zenith angles (SZA) near $90^{\circ}$, retrieved AODs are strongly affected by uncertainties in the relative optical airmass (here called airmass for brevity) of the aerosols and other constituents along the (generally refracted) line of sight (LOS) between instrument and sun. For any given constituent and/or wavelength, airmass is defined as the ratio of LOS optical thickness (OT) to vertical OT. (In this paper we define vertical OT as optical depth $(O D)$, and restrict use of $O D$ to apply only to the vertical.) For $S Z A$ near $90^{\circ}$, airmass of a given attenuator is sensitive to its vertical profile shape. Uncertainties in such vertical profiles therefore produce corresponding uncertainties in the associated airmass. To reduce dependence of the AATS-satellite comparisons on airmass, we perform the comparisons in LOS transmission and LOS OT as well as in vertical OT (or optical depth).

This paper shows AATS-satellite comparisons from DC-8 flights on five days: 19, 21, 24, 29, and 31 January 2003. Figure 1 shows the DC-8 flight tracks for those days in relation to occultation locations of SAGE III and POAM III, superimposed on maps of modified potential vorticity. This paper also shows AATS-DIAS comparisons for each of those five days, plus a sixth, 2 February 2003.

Figure 2 shows vertical profiles of multiwavelength aerosol extinction retrieved by SAGE III for the four occultations near the DC-8 flight track on 19, 24, 29, and 31 January 2003. Figure 3 shows analogous POAM III results for the occultation near the DC- 8 track on 19 January and the three occultations near the DC-8 on 21 January. In this paper, to obtain satellite $A O D$ values for comparison to AATS $A O D$ s, we integrate vertically the latest versions of SAGE III and POAM III aerosol extinction profiles available at the time of writing, i.e., version 3.00 (v3.00) for SAGE III (e.g., Taha et al., 2004) and version 4 (v4) for POAM III (e.g., Randall et al., in preparation, $2005^{1}$ ).

Before comparing the satellite results to AATS, we first use selected vertical profiles (some from previous versions

\footnotetext{
${ }^{1}$ Randall, C. E., Lumpe, J. D., Bevilacqua, R. M., Hoppel, K. W., et al.: POAM III validation: An update for version 4.0 aerosol, in preparation, 2005.
}

of SAGE III and POAM III) to help illustrate how airmass depends on extinction vertical profile, wavelength, and other factors.

\section{Airmass dependence on $S Z A$, extinction profiles, wavelength, and DC-8 altitude}

Figure 4 shows how vertical distributions of different constituents affect airmass and its dependence on SZA. The ozone profiles shown are from SAGE III and POAM III occultations near DC-8 flights reported in this paper and flown on the dates shown (e.g., 0119 is 19 January 2003). The aerosol profiles are from the same SAGE III and POAM III occultations, plus two composite or modified profiles (labeled "SG0119AATSlay" and "Liv Aero Model" and described further below). Airmass results in the right frame were computed using a new algorithm (Yee al., 2002; DeMajistre and Yee, 2002; Vervack et al., 2002), which is essential to this study since it provides results for $S Z A<90^{\circ}$, $=90^{\circ}$, and $>90^{\circ}$, all of which were encountered in the DC- 8 measurements reported here.

Results in Fig. 4 show some general features of note. For example, for a DC-8 altitude of $10 \mathrm{~km}$, ozone airmass is in general less than aerosol airmass, and it depends less steeply on SZA. These results are caused by the fact that the ozone profile centroid is farther above the DC- 8 than is the aerosol extinction profile centroid (see, e.g., Thomason et al., 1983). Aerosol airmasses at $10 \mathrm{~km}$ and $S Z A=90^{\circ}$ range from $\sim 32$ to $\sim 42$, a span of $\pm 14 \%$ of the mean. Changing the shape of an aerosol profile by increasing its extinction just above the DC-8 but not elsewhere can increase its airmass significantly. For example, the aerosol profile "SG0119AATSlay" is the same as that labeled "SAGE0119", except that its extinction is roughly doubled (increased to $6.5 \times 10^{-3} \mathrm{~km}^{-1}$ ) in a layer between 8 and $11 \mathrm{~km}$. Note that this increased extinction near the DC-8 increases aerosol airmass at $10 \mathrm{~km}$ and $90^{\circ}$ from $\sim 37.5$ to $\sim 42.5$, or by $13 \%$. The aerosol profile "Liv Aero Model" is a composite of typical high-latitude SAGE II and tropospheric aerosol extinction profiles. Its shape is not very different from the molecular density profile shown (which is the MODTRAN subarctic winter model). As shown in Fig. 4, this similarity in vertical distributions yields very similar curves of airmass vs. SZA.

For a given ozone number density profile, the extinction profile has the same shape for any wavelength (apart from any temperature or pressure dependences that vary with wavelength - which we neglect in this paper). The same is true for a given molecular number density profile. Hence, apart from the wavelength dependence of the light path caused by refraction, ozone and Rayleigh airmasses are independent of wavelength. In contrast, a given aerosol number density profile can have different shapes of extinction profiles at different wavelengths (this is illustrated by the profiles in Figs. 2 and 3). Therefore, aerosol airmass is in general 

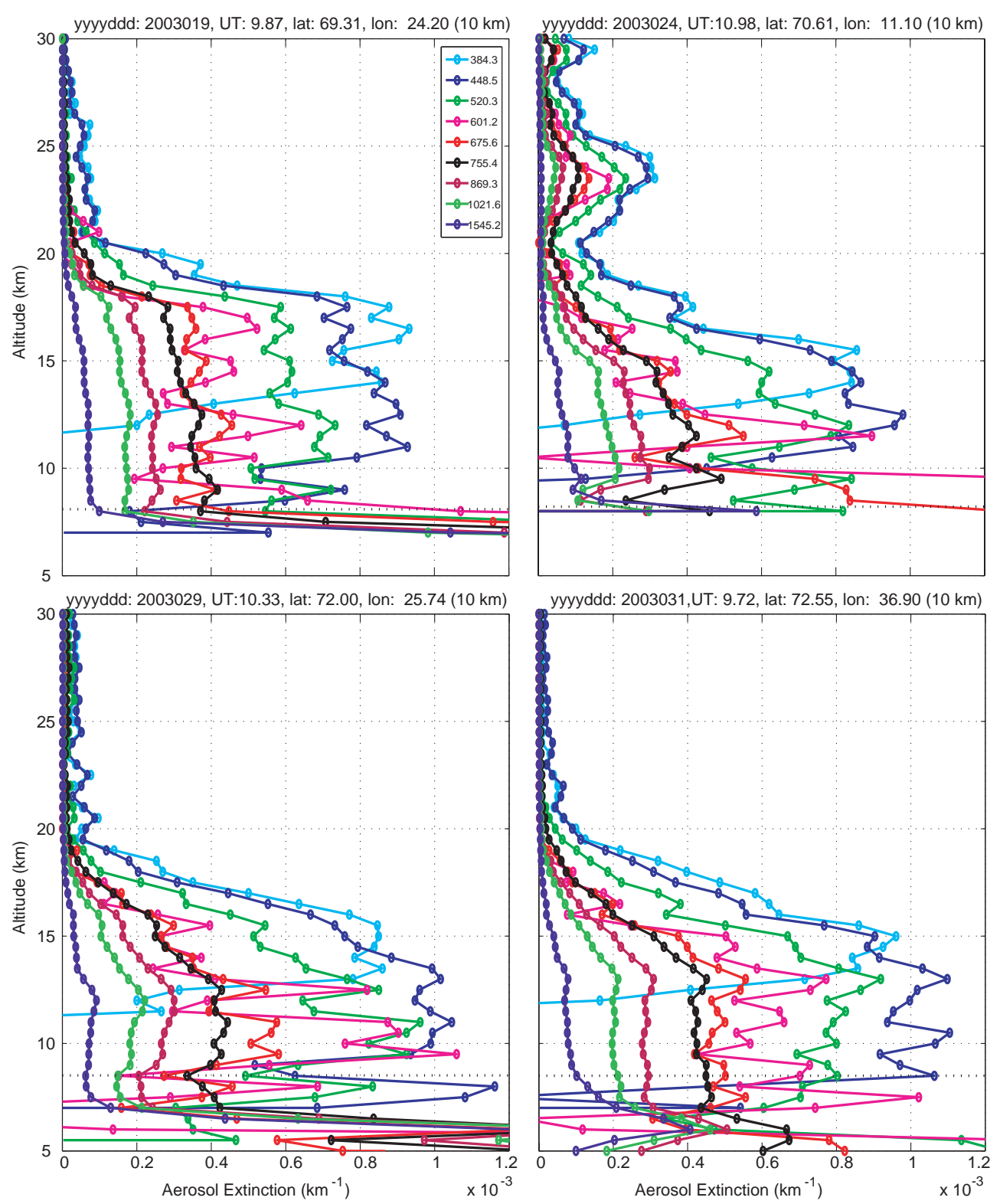

Fig. 2. SAGE III v3.00 vertical profiles of aerosol extinction for the occultation events near the DC- 8 on 19, 24, 29 , and 31 January.

a function of wavelength. Whereas the aerosol airmass results in Fig. 4 are for two very similar wavelengths $(755.4 \mathrm{~nm}$ for SAGE III and $779.4 \mathrm{~nm}$ for POAM III), Fig. 5 illustrates the dependence of aerosol airmass on wavelength over the range 384 to $1545 \mathrm{~nm}$. Shown are aerosol extinction profiles and corresponding airmass results for the SAGE III occultation near the DC-8 on 24 January 2003. For these cases, aerosol airmass increases with increasing wavelength, a consequence of the fact that increasingly longer wavelengths have extinction profiles with lower altitude centroids. (These lower centroids result from larger particles being increasingly dominant at lower altitudes, owing to sedimentation or to growth in higher relative humidity). Results in the lower rightmost frame of Fig. 5 show that, at $10.5 \mathrm{~km}$ and $90^{\circ}$, increasing the wavelength from 449 to $1545 \mathrm{~nm}$ causes the airmass to increase from $\sim 30$ to $\sim 43$. This range is $\pm 18 \%$ of the mean airmass, 36.5. Note that the intermediate wavelength, $755 \mathrm{~nm}$, has airmass very near this mean. Note also that we have excluded the shortest wavelength, $384 \mathrm{~nm}$, from this discussion, since SAGE III extinction profiles for this wavelength do not extend this low in altitude, owing to signal depletion. We will return to these results when we discuss the sensitivity of our $A O D$ retrievals to the assumptions in our analyses. 

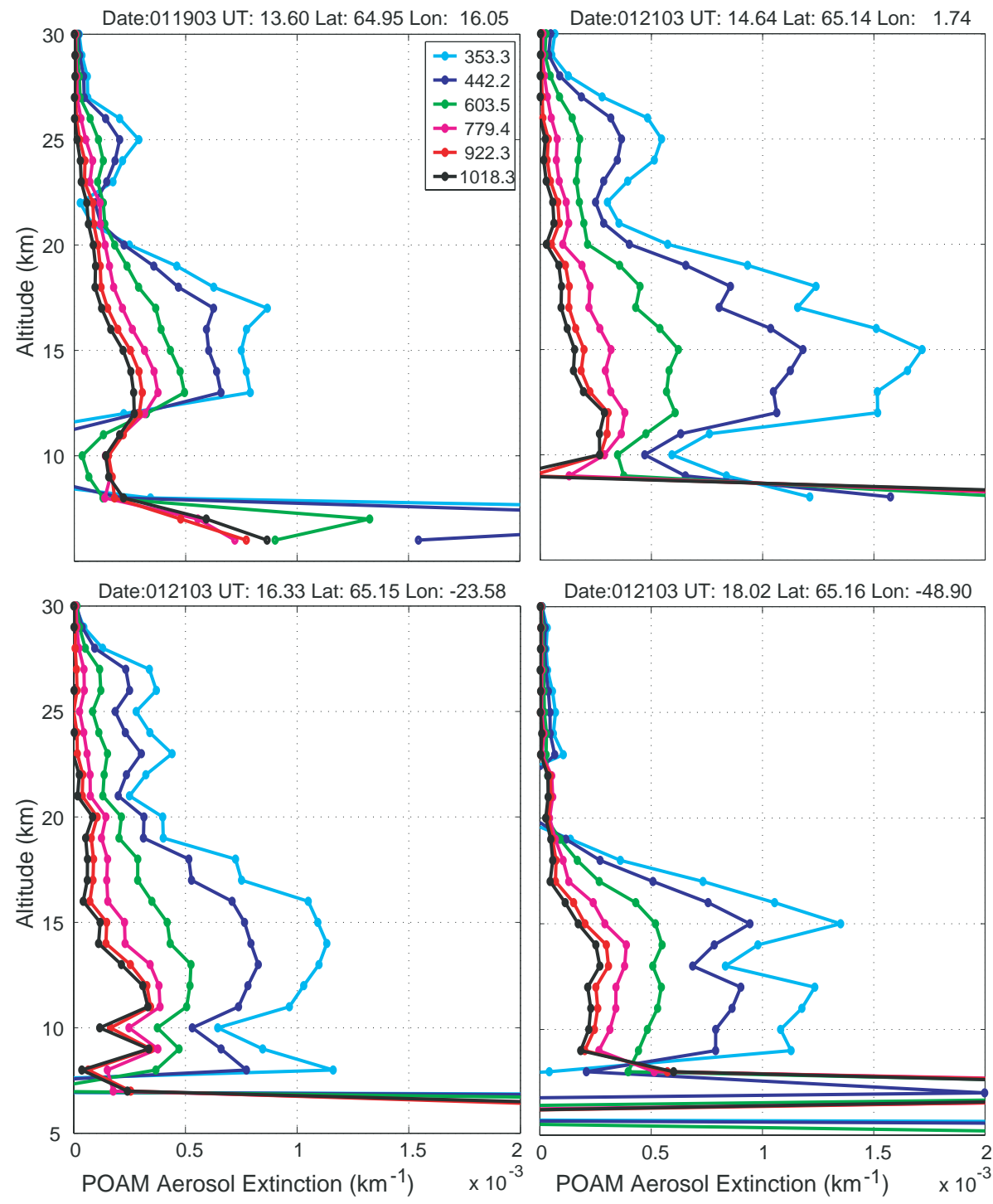

Fig. 3. POAM III v4 vertical profiles of aerosol extinction for the occultation events near the DC-8 on 19 and 21 January 2003.

Figure 5 also illustrates the height dependence of airmass. In this case aerosol airmasses at $S Z A=90^{\circ}$ are less at $8.5 \mathrm{~km}$ than $10.5 \mathrm{~km}$, because most aerosol extinction is farther above $8.5 \mathrm{~km}$ than $10.5 \mathrm{~km}$.

Finally, Fig. 5 also compares airmasses computed by the Yee algorithm to those computed by the algorithm we previously used (Thomason et al., 1983), called UA in Fig. 5. The UA algorithm's range of validity is $S Z A<90^{\circ}$. Within that range, the Yee and UA algorithms give quite similar results, as can be seen by comparing the two rightmost columns of Fig. 5. For all the cases we have investigated, we find that the Yee and UA airmass results for ozone, Rayleigh, and aerosol agree to within $2 \%$ for SZA in the UA range of validity, i.e., $S Z A<90^{\circ}$.
Figure 6 (bottom frame) shows time dependent airmasses, $m_{R}, m_{O 3}$, and $m_{a}$, for Rayleigh, ozone, and aerosol, respectively, obtained by applying the Yee airmass algorithm to the SZAs and altitudes (top frame) experienced by the DC-8 on 19 January 2003 near the SAGE III occultation identified in the top left frame of Fig. 2. Aerosol airmass results were computed using the SAGE III aerosol extinction profile at wavelength $755 \mathrm{~nm}$. For each time, airmass results are shown for two values of $S Z A: 90^{\circ}$ (apparent) and $S Z A_{\text {meas }}$, the $S Z A$ at the measurement time. The changes in $m_{i}\left(S Z A_{\text {meas }}\right)$ with time result from changes in both $S Z A_{\text {meas }}$ and DC-8 altitude. Changes in $m_{i}\left(90^{\circ}\right)$ result from changes in DC-8 altitude alone. These airmass factors, and all others used to analyze AATS-14 data in this paper and in Livingston et al. (2005), were obtained by interpolation in matrices of airmass factors that were pre-calculated as a function of SZA (at $0.1^{\circ}$ 

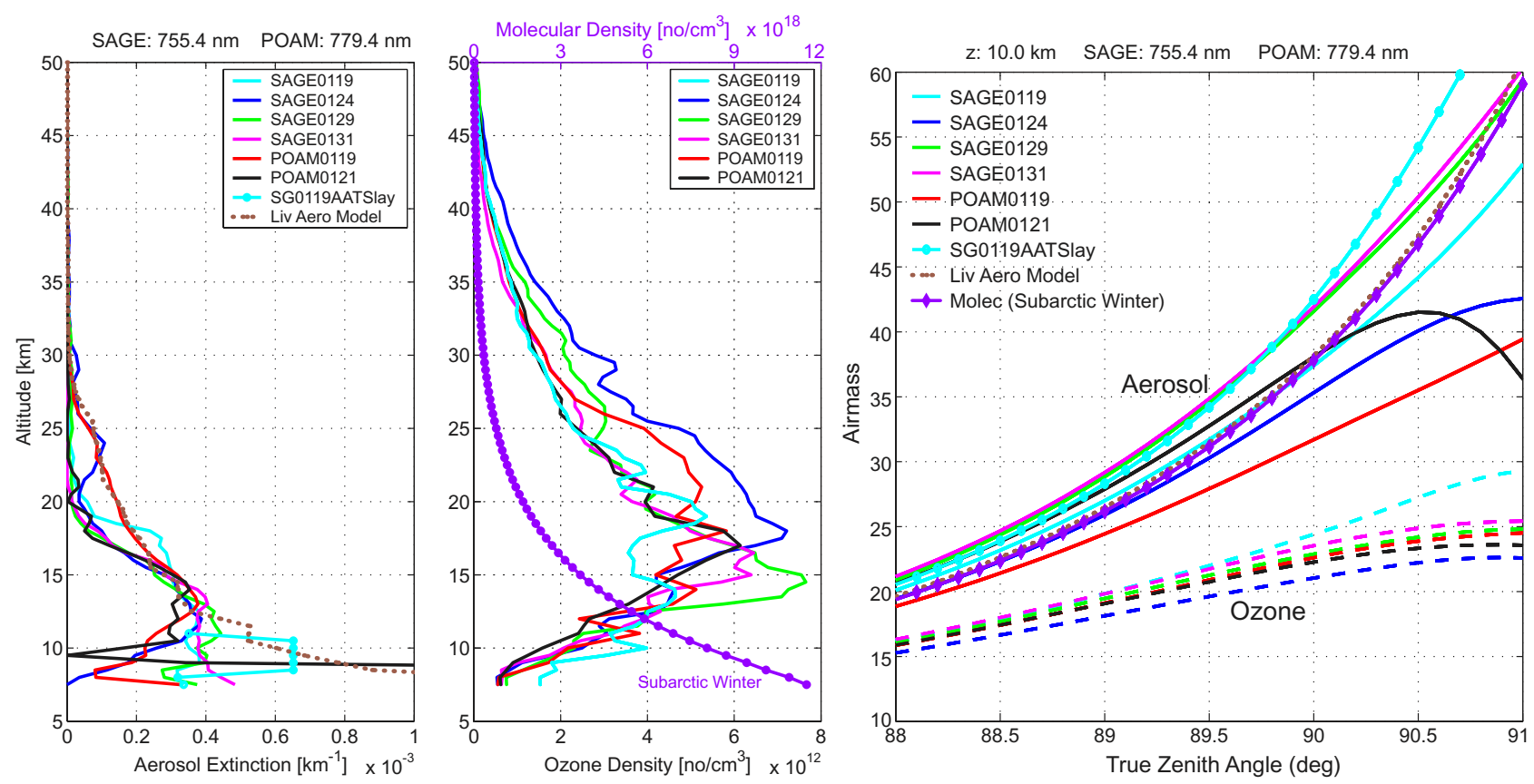

Fig. 4. Left frames: Representative vertical profiles of aerosol extinction and of ozone and molecular number density. Aerosol and ozone profiles are from SAGE III and POAM III retrievals near DC-8 flights on the dates shown. Aerosol profiles are for one SAGE III wavelength $(775.4 \mathrm{~nm})$ and one POAM III wavelength $(779.4 \mathrm{~nm})$. The molecular density profile is the MODTRAN subarctic winter model. Right frame: Corresponding results for airmass calculated for altitude $10 \mathrm{~km}$ using the method of DeMajistre and Yee (2002) and the constituent profiles in the left frames.

resolution) and altitude (at $0.5-\mathrm{km}$ resolution) for a particular SAGE III or POAM III occultation event.

Figure 7 shows analogous results for the DC- 8 flight and nearby SAGE III occultation on 29 January 2003. Not shown for brevity are analogous plots for the 24 and 31 January DC-8 flights, which experienced a range of SZA within those covered by the 19 and 24 January flights.

The following section presents results that use these airmass computations, both to solve for AODs from AATS measurements and to convert AATS transmissions measured at $S Z A_{\text {meas }}$ to transmission at an apparent (refracted) $S Z A$ of $90^{\circ}$.

\section{AATS-SAGE comparisons}

\subsection{AATS-14 and SAGE III AODs from conventional anal- yses}

We first obtained AODs from AATS and SAGE measurements by conventional analyses. That is, we obtained AATS $A O D$ s using the method described in the Appendix of Russell et al. (1993), and we obtained SAGE AODs by vertically integrating the SAGE aerosol extinction profiles in Fig. 2 above the DC-8 altitude. AATS AOD results at two selected wavelengths, 519 and $864 \mathrm{~nm}$, are shown in Figs. 6 and 7 as time series, along with time series of DC- 8 altitude and distance from the SAGE III tangent point. Figure 8 shows the AATS results as $A O D$ spectra (green stars labeled "AATS, conventionally derived"), along with the SAGE $A O D$ results (green circles labeled "SAGE v3.00, Aer Ext Integral").

The results in Fig. 8 show that the conventional analyses yield SAGE AODs that are systematically less than AATS $A O D$ s, and that the percentage difference between the SAGE and AATS AODs increases with wavelength.

Because of these systematic $A O D$ differences, and because of the strong dependences of AATS-derived $A O D$ s on airmass, of SAGE-derived $A O D$ s on path-length matrices, and of both AATS- and SAGE-derived AODs on Rayleigh scattering and absorbing gas retrievals, we have also compared AATS and SAGE in the more fundamental result, transmission of the direct beam. We have also derived $A O D$ s from the AATS and SAGE transmissions using a more transmissionoriented analysis, which helps to show the relative roles of gas and aerosol attenuation at the various wavelengths. These transmission-oriented results are described in the following subsections.

Before presenting the transmission-oriented results we also note that we have performed a "modified conventional" AATS analysis, which excludes all times that had apparent $S Z A>90^{\circ}$. (Such times can be identified in Figs. 6-7.) Our motivation for doing this was that, for such SZA, the AATS LOS passes through altitudes below the DC-8, which are not included in the SAGE extinction integrals used to get 


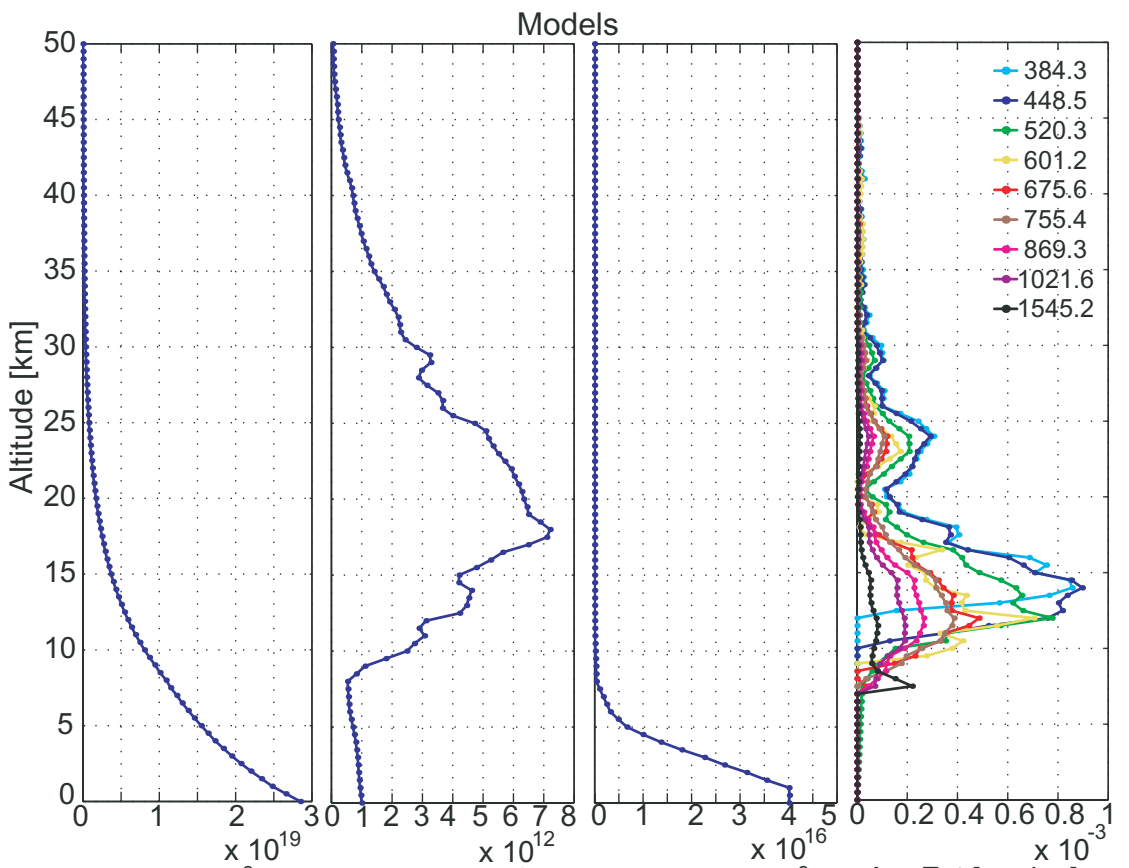

Molec $\left[\mathrm{no} / \mathrm{cm}^{3}\right] \quad$ Ozone $\left[\mathrm{no} / \mathrm{cm}^{3}\right] \quad$ Wat Vap $\left[\mathrm{no} / \mathrm{cm}^{3}\right] \quad$ Aer Ext $[\mathrm{per} \mathrm{km}]$
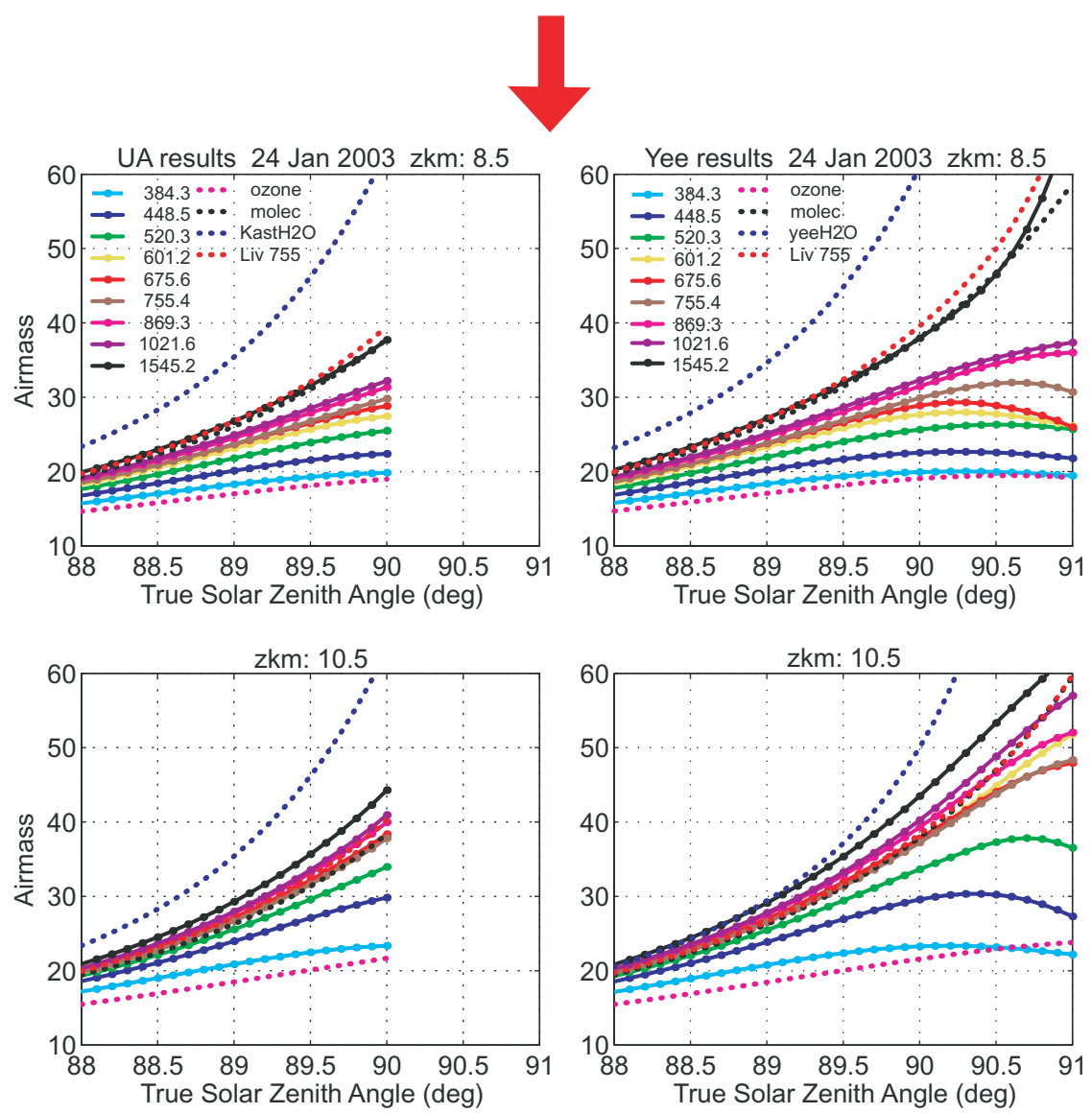

Fig. 5. Comparison of airmass results from the methods of DeMajistre and Yee (2002, labeled Yee) and Thomason et al. (1983, labeled UA), for different wavelengths of aerosol extinction and for molecular, ozone, and water vapor number density. Profiles in the left frames yield the airmasses in the right frames for two altitudes: $8.5 \mathrm{~km}$ (top row) and $10.5 \mathrm{~km}$ (bottom row). 


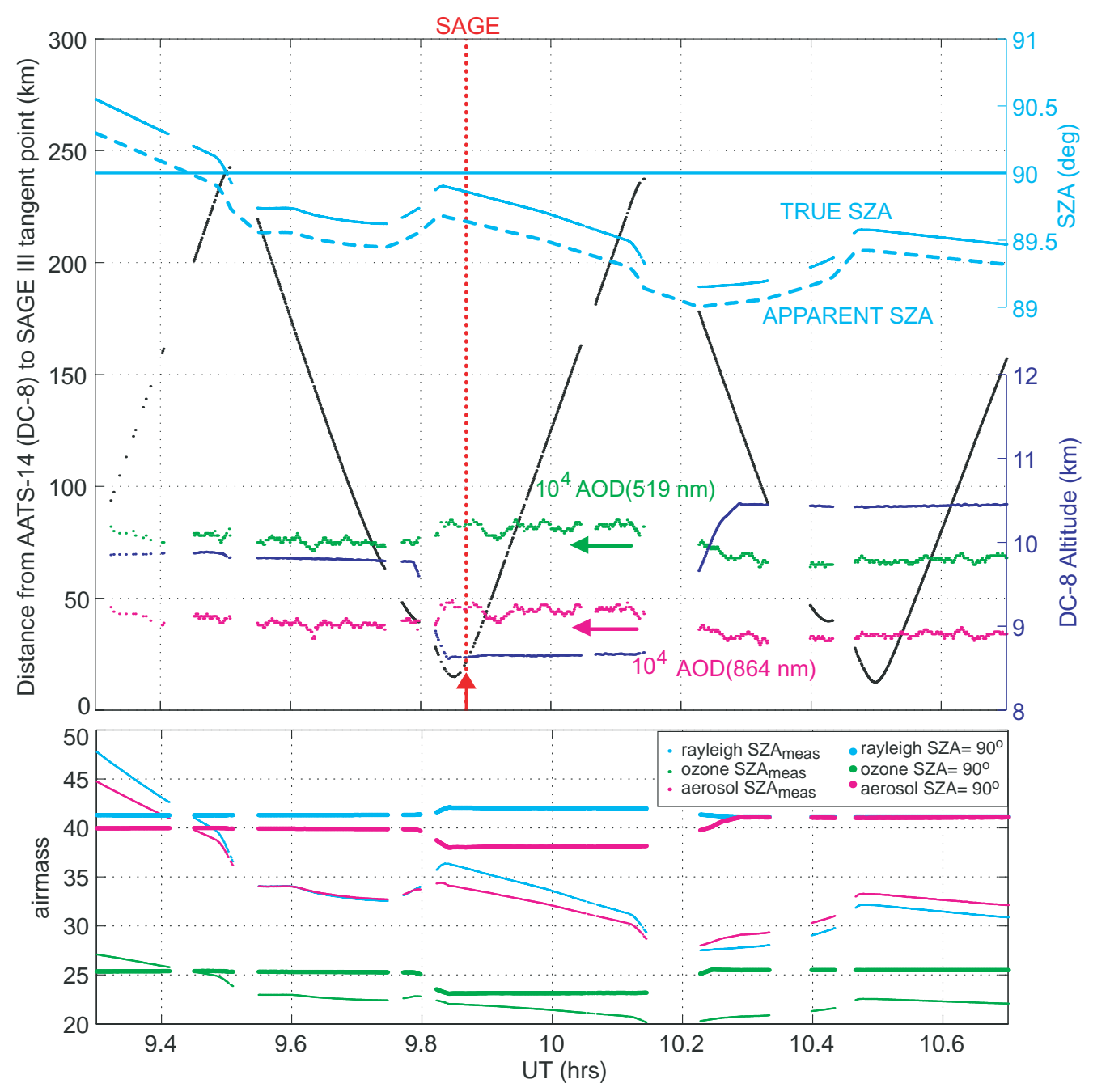

Fig. 6. Conditions and results for the DC-8 flight of 19 January 2003. Top: DC-8 altitude, distance from SAGE III 10-km tangent point, and true and apparent (refracted) $S Z A$, with $A O D$ retrieved from AATS-14 at two wavelengths. Red vertical dotted line marked by red arrow and "SAGE" shows time of SAGE III tangent at $10 \mathrm{~km}$ altitude. Bottom: Airmasses for Rayleigh, ozone, and aerosol (755 nm), at $S Z A_{m e a s}$ and apparent $S Z A=90^{\circ}$, computed using the Yee algorithm. Results shown used SAGE III version 2.00 profiles, but results using version 3.00 differ by $<2 \%$.

SAGE $A O D$ above the DC-8. AATS AODs from the modified conventional analyses (not shown for brevity) differed from the conventional results in Fig. 8 by $8 \%$ or less at all wavelengths, and hence did little to reduce the AATS-SAGE differences.

\subsection{AATS-14 and SAGE III transmission measurements}

Figure 9 shows vertical profiles of transmission measured by SAGE III during four solar occultation events that were the focus of DC-8 maneuvers on 19, 24, 29, and 31 January 2003 during SOLVE II. These are full-limb atmospheric transmissions, meaning that they describe transmission through the full atmospheric limb between the spaceborne SAGE III instrument and the Sun. Results are shown for five selected
SAGE III wavelengths, which are defined by pixel groups in the array detector of the SAGE III spectrometer. The SAGE III transmission measurements are made by scanning its pointing mirror up and down across the Sun as SAGE III's movement in its orbit makes the Sun appear to rise or set (NASA Langley Research Center, 2002). The left column of Fig. 9 shows the altitude-vs-time trace of the tangent point of the lowest atmospheric shell traversed by the refracted line of sight (LOS) from SAGE III to the Sun. Because refraction is wavelength dependent, the altitude-vs-time traces are also wavelength dependent. The result shown is for wavelength $449.9 \mathrm{~nm}$ (SAGE III pixel group 21).

As Fig. 9 shows, the scans across the sun produce many transmission measurements for a given tangent altitude interval. The transmission measurements initially identified as 


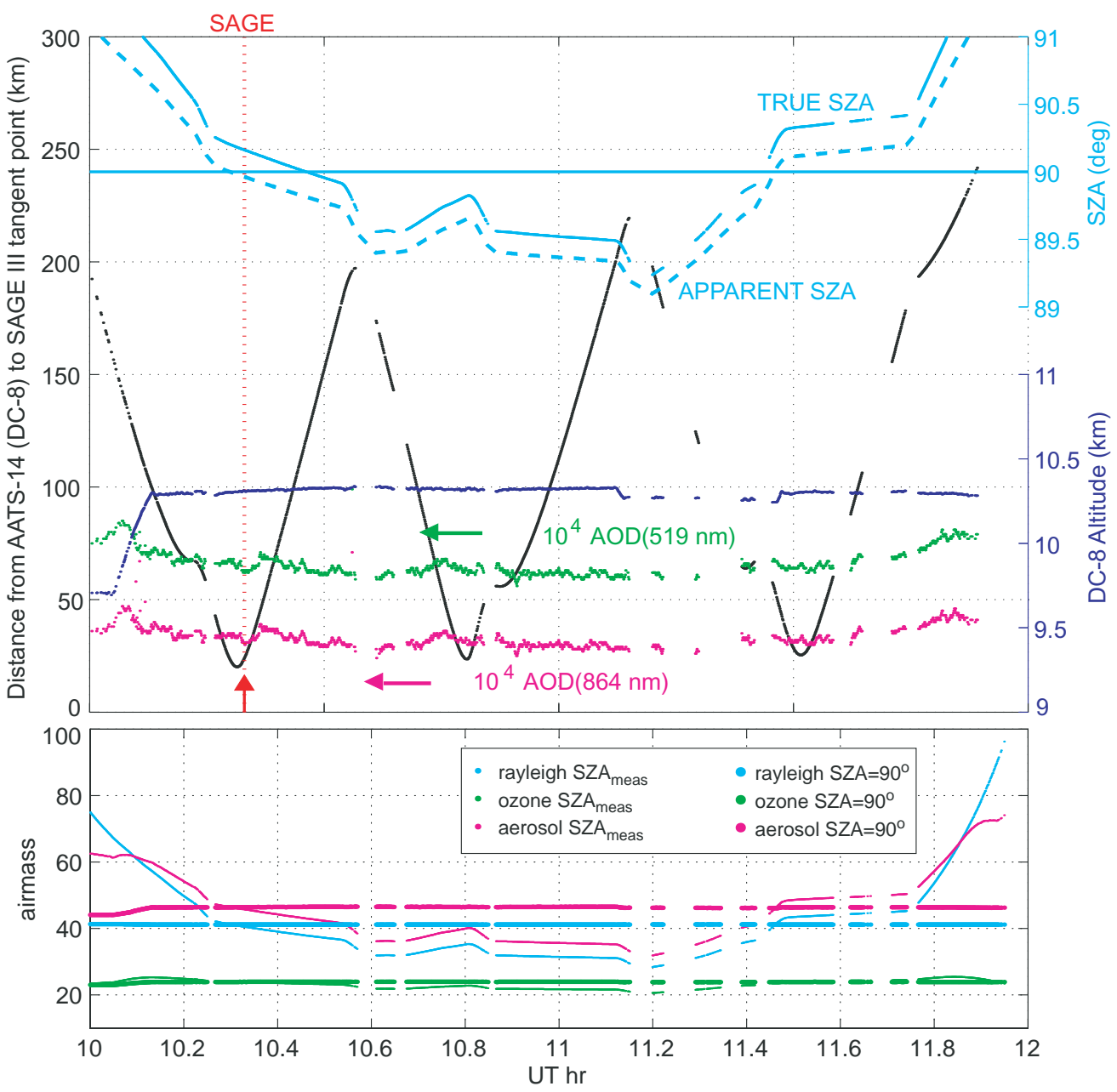

Fig. 7. As in Fig. 6, but for 29 January 2003. Airmass results shown used SAGE III version 2.00 profiles, but results using version 3.00 differ by $<6 \%$.

"good" by the SAGE III retrieval algorithm are shown by the points and curves labeled "SAGE III, "good"' in Fig. 9. Other points, identified as "dropped" by the algorithm, are also shown. The SAGE III algorithm groups transmissions into altitude bins $0.5 \mathrm{~km}$ thick, and archives the median of each group of "good" points. These archived median values are labeled "SAGE III archived" in Fig. 9. Using median values reduces or eliminates the influence of outliers among the points initially identified as "good". Such outliers can be seen in Fig. 9. Outliers can be caused by misregistration of transmitted solar intensity values near scan edges (i.e., within the solar limb-darkening region), among other reasons.

Also shown in Fig. 9 are transmission results from AATS-14 measurements. AATS transmissions are shown both as measured at the AATS measurement $S Z A, S Z A_{\text {meas }}$, and as converted from $S Z A_{\text {meas }}$ to the apparent (refracted) $S Z A$ of $90^{\circ}$ that occurs along the SAGE limb viewing path at its tangent point. This conversion process is explained in Sect. 3.3. All AATS transmissions in Fig. 9 have also been squared to convert from half limb to full limb. This squaring assumes that transmission is equal in the two limb halves (i.e., from DC- 8 to the Sun and from DC- 8 away from the Sun). Equal transmission in the two limb halves is just a special case of the homogeneity in spherical shells that is assumed by satellite limb inversion algorithms. We discuss this assumption further in Sect. 6.

As elaborated in Sect. 3.3, the conversion of AATS transmission from $S Z A_{\text {meas }}$ to $90^{\circ}$ depends on differences between airmasses at $S Z A_{\text {meas }}$ and at $90^{\circ}$, rather than on airmasses themselves. It is thus less sensitive to airmass than is, e.g., the conversion from transmission to vertical $O D$. This is increasingly so as apparent $S Z A_{\text {meas }}$ approaches or equals $90^{\circ}$, as it did on several DC- 8 flights (see the $S Z A$ curves in Figs. 6-7). Examples of $S Z A_{\text {meas }}$ equaling $90^{\circ}$ (apparent) in Fig. 9 are given by the data points for 24, 29, and 31 January where transmissions labeled "AATS, $90^{\circ}$ " equal those labeled "AATS, $S Z A_{\text {meas }}$ ". 


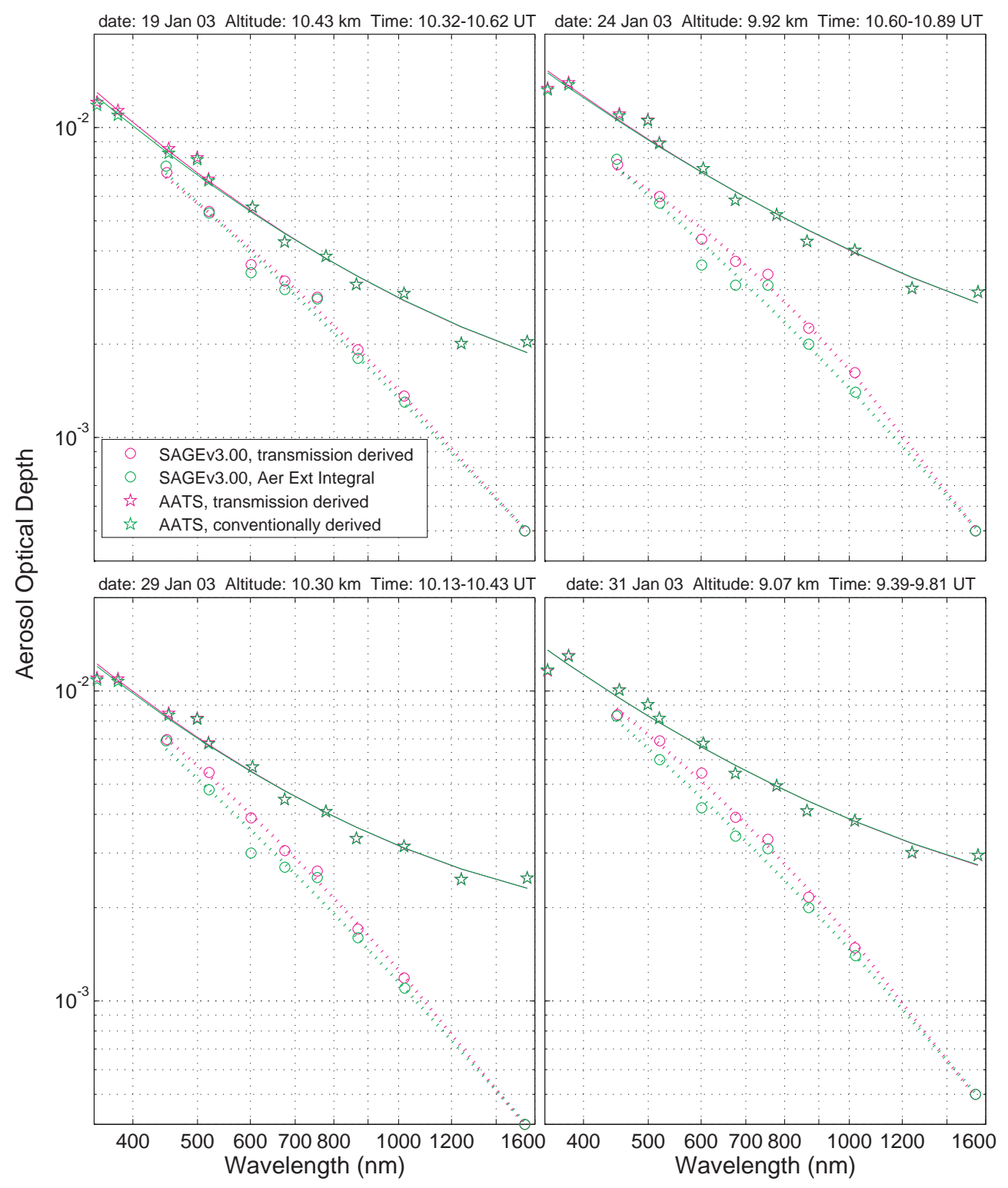

Fig. 8. Comparison of AOD spectra from AATS-14 and SAGE III measurements on 19, 24, 29, and 31 January 2004.

\subsection{Converting AATS transmissions to $90^{\circ}$ refracted $S Z A$}

Converting transmission $T$ from one $S Z A$ to another requires knowing the components (or factors) making up transmission, as well as the relative vertical distribution of each component above the observation altitude. As noted above, the vertical distributions are needed to determine the SZA dependence of the airmasses for all components with significant attenuation. That is,

$T(S Z A)=$

$T_{a}(S Z A) T_{R}(S Z A) T_{N_{2}}(S Z A) T_{O_{3}}(S Z A) T_{O_{2}-O_{2}}(S Z A) \ldots$, where subscripts indicate the attenuating component ( $a$ for aerosol, $R$ for Rayleigh, etc.), and

$T_{i}(S Z A)=\exp \left[-2 m_{i}(S Z A) O D_{i}\right]$

where $m_{i}$ and $O D_{i}$ are the airmass and $O D$ of constituent i. The factor 2 gives transmission for the full path into and out of the atmosphere at $S Z A$ (which is the full limb path when refracted - i.e., apparent $\left.-S Z A=90^{\circ}\right)$. Any $T$ in this paper is for this full path.

For each measurement time we solved Eq. (1) for $T_{a}$ as:

$T_{a}(S Z A)=$

$T(S Z A) /\left[T_{R}(S Z A) T_{N O_{2}}(S Z A) T_{O_{3}}(S Z A) T_{O_{2}-O_{2}}(S Z A) \ldots\right]$. 


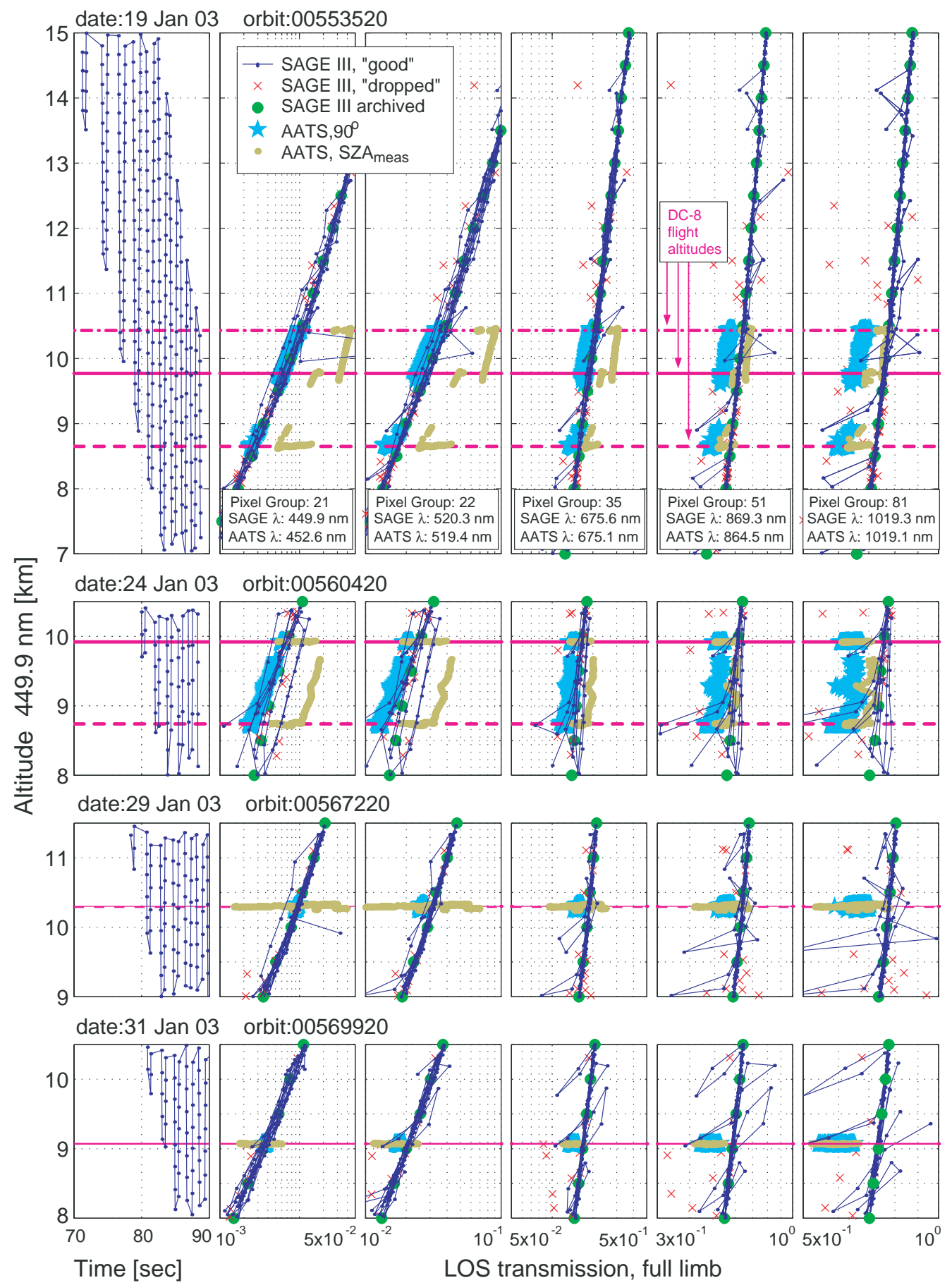

Fig. 9. SAGE III vertical profiles of transmission at representative wavelengths for the occultation events near the DC-8 on $19,24,29$, and 31 January, with near-coincident AATS transmission values at the AATS measurement $S Z A, S Z A_{m e a s}$, and converted to apparent $S Z A=90^{\circ}$.

To convert from the apparent SZA of the AATS measurement, $S Z A_{\text {meas }}$, to an apparent $S Z A$ of $90^{\circ}$ we used Eq. (2) at $S Z A_{\text {meas }}$ and $90^{\circ}$ to obtain

$$
\begin{aligned}
& T_{i}\left(90^{\circ}\right)= \\
& T_{i}\left(S Z A_{\text {meas }}\right) \exp \left\{2\left[m_{i}\left(S Z A_{\text {meas }}\right)-m_{i}\left(90^{\circ}\right)\right] O D_{i}\right\},
\end{aligned}
$$

with $m_{i}$ and $O D_{i}$ inputs as described below. Line-of-sight optical thicknesses, LOSOT, were obtained as

$\operatorname{LOSOT}_{i}(S Z A)=-\ln \left[T_{i}(S Z A)\right]$

and aerosol optical depths (AODs) as

$O D_{a}=\operatorname{LOSOT}_{a}(S Z A) /\left[2 m_{a}(S Z A)\right]$. 

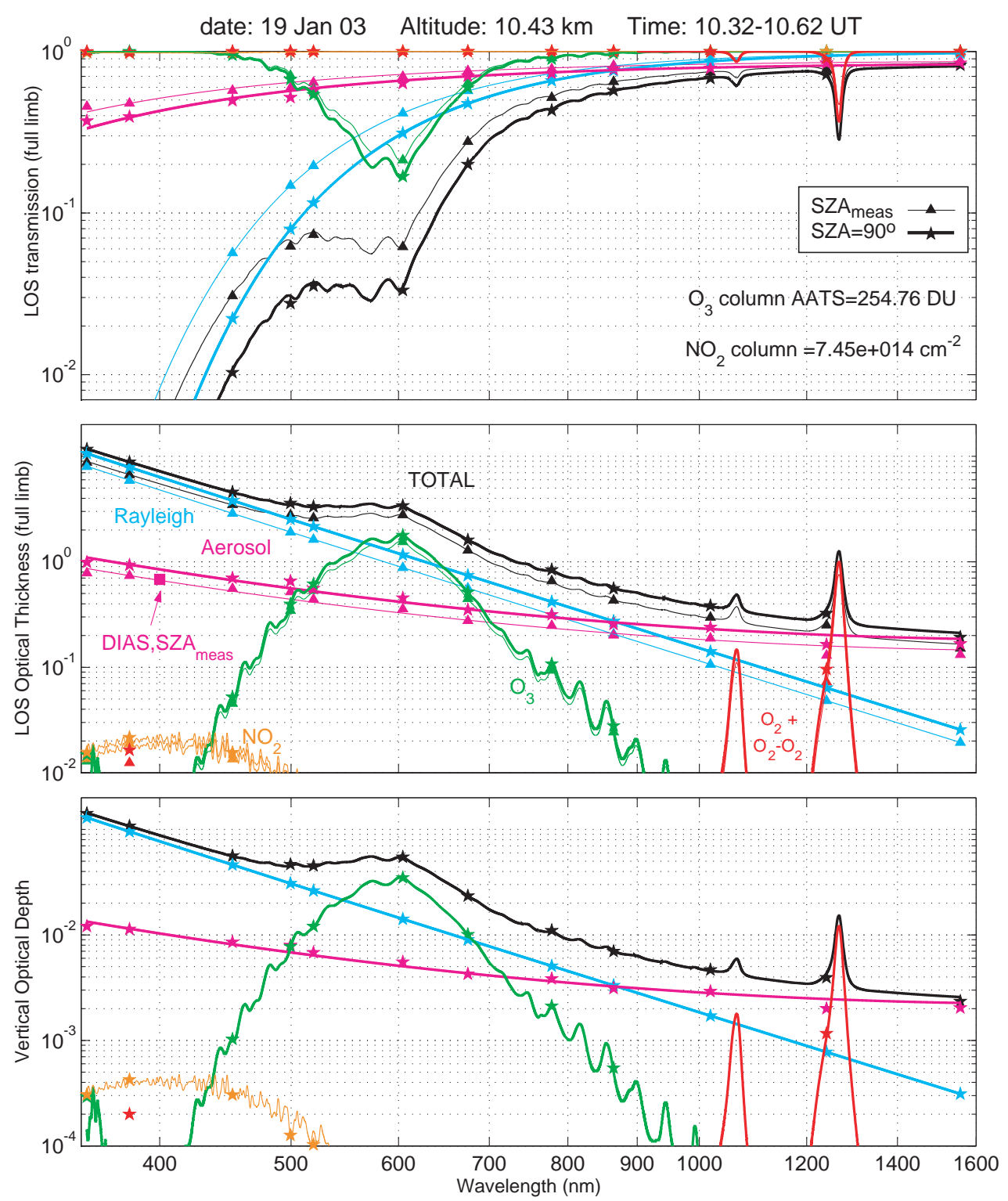

Fig. 10. AATS transmission, LOSOT, and $O D$, for components and totals, for 19 January 2003 at $10.43 \mathrm{~km}$. Top frame: transmission at $S Z A_{\text {meas }}$ and converted to $90^{\circ}$; middle frame: $L O S O T$ at $S Z A_{\text {meas }}$ and converted to $90^{\circ}$; bottom frame: $O D$.

This conversion process is illustrated in Fig. 10 for the DC-8 leg at $10.43 \mathrm{~km}, 10.32-10.62$ UT on 19 January 2003. As shown by the top frame of Fig. 6, during 10.32-10.62 UT, the DC-8 was within $100 \mathrm{~km}$ of the SAGE III tangent point, and the apparent (refracted) $S Z A$ varied between $\sim 89.0^{\circ}$ and $89.4^{\circ}$. Quantities that depend on $S Z A$ (i.e., $T_{i}(S Z A)$ in the top frame of Fig. 10, and $\operatorname{LOSOT}_{i}(S Z A)$ in the middle frame) were computed at each measurement time using the time-dependent airmasses, $m_{R}, m_{O 3}$, and $m_{a}$, shown in the bottom frame of Fig. 6. Results for $T_{i}(S Z A)$ and $\operatorname{LOSOT}_{i}(S Z A)$ were then averaged over 10.32-10.62 UT to obtain the illustrative results shown in Fig. 10.
$O D_{i}$ inputs used in Fig. 10 were obtained as follows:

- Rayleigh: Pressure at DC-8 and wavelength, using the equation of Bucholtz et al. (1995), which gives results that differ negligibly (e.g., by $0.06 \%$ to $0.02 \%$ for $\lambda$ between 380 and $1019 \mathrm{~nm}$ ) from results obtained using Bodhaine et al. (1999).

- $\mathrm{NO}_{2}$ : SAGE III retrieved column amount with wavelength-dependent cross sections (see below).

- Ozone: AATS-14 retrieved column amount (Livingston et al., 2005) with wavelength-dependent cross sections (see below). 

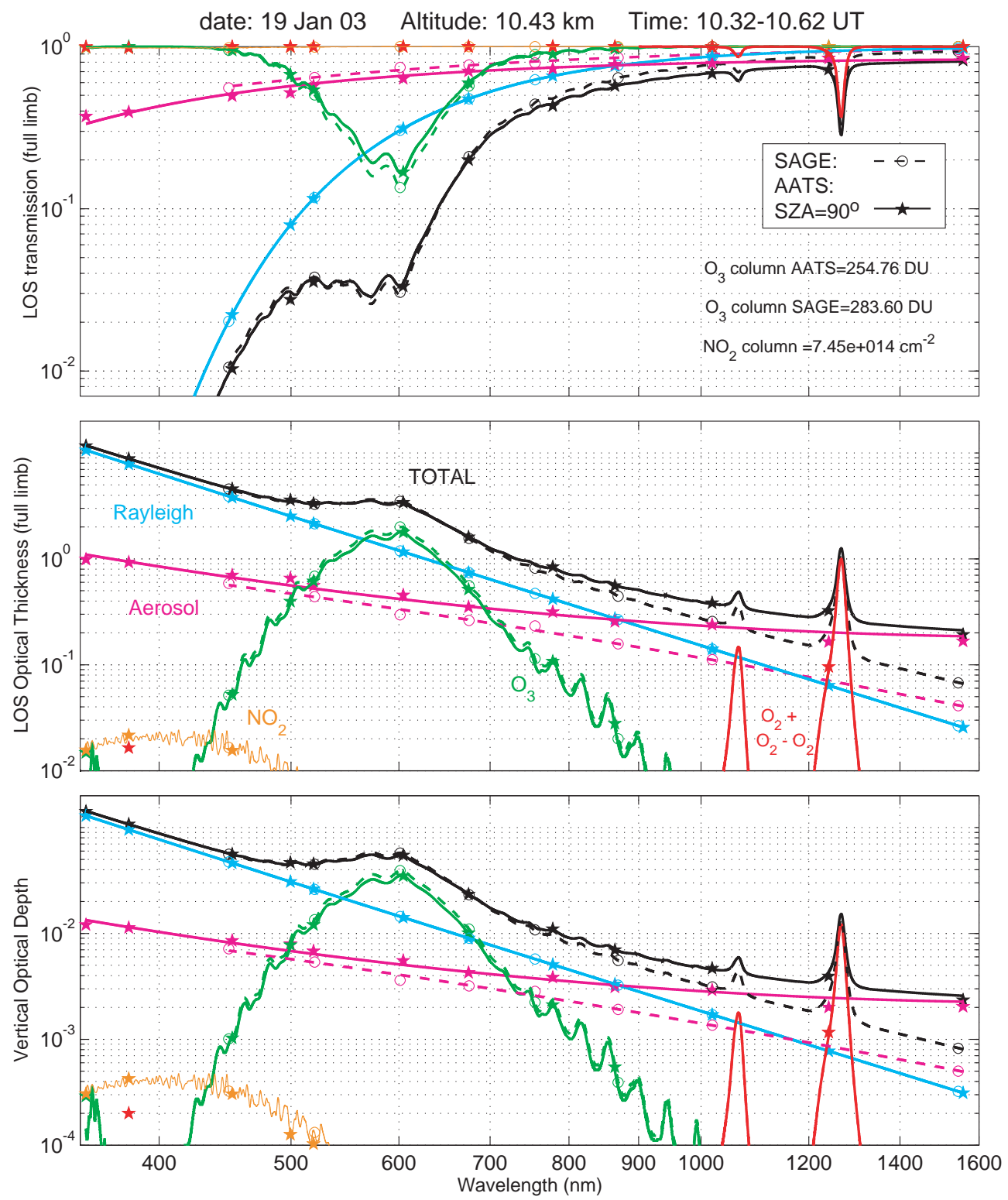

Fig. 11. Comparison of SAGE and AATS transmission, LOSOT, and OD, by components and totals, for 19 January 2003 at $10.43 \mathrm{~km}$. All AATS results for $T$ and $L O S O T$ have been converted from $S Z A_{\text {meas }}$ to apparent $S Z A 90^{\circ}$.

- $\mathrm{O}_{2}-\mathrm{O}_{2}$ : Midlatitude summer atmosphere for $\mathrm{O}_{2}$, with $\mathrm{O}_{2}-\mathrm{O}_{2}$ calculated as a function of altitude, plus wavelength-dependent cross sections (see below).

As shown by Livingston et al. (2005), the AATS retrieved ozone columns agree with the corresponding SAGE III values to an RMS difference of 18 Dobson units (DU), or $\sim 6 \%$. The largest AATS-SAGE difference, $30 \mathrm{DU}$, was observed on 19 January 2003. Ozone column spatial variability observed by AATS along the flight path was comparable to these AATS-SAGE ozone differences. The $O D$ of $30 \mathrm{DU}$ of ozone is 0.004 at $605 \mathrm{~nm}$, the peak of the Chappuis absorption band. Wavelength-dependent gas absorption cross-sections were computed using the Line-by-Line Radiative Transfer Model LBLRTM 6.01 (Clough and Iacono, 1995) with the CKD 2.4.1 continuum model using the High Resolution Transmission HITRAN 2000 (v11.0) line-list (Rothman et al., 2001; Rothman and Schroeder, 2002). $\mathrm{NO}_{2}$ cross-sections not included in LBLRTM 6.01 were taken from Harder et al. (1997). Absorbing gas optical depth and transmission values shown in Fig. 10 as data points at AATS14 wavelengths take into account the interference filter function of each AATS-14 channel. Typical channel full widths at half maximum (FWHM) are $5 \mathrm{~nm}$. Although the absorbing gas optical depth and transmission values in Fig. 10 do not account for solar spectral variations within the AATS 


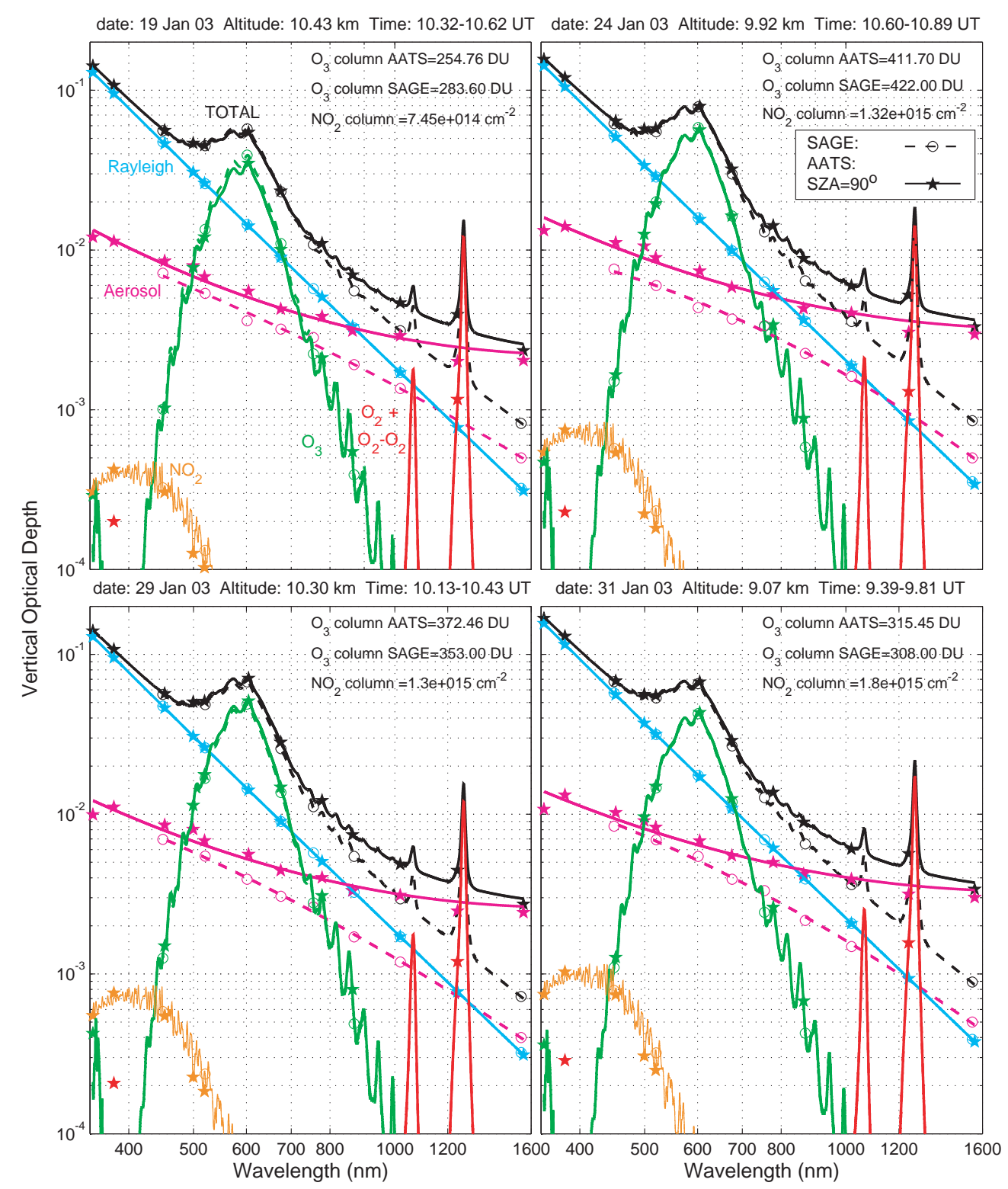

Fig. 12. Comparison of AATS and SAGE vertical $O D$ (total and components) for 19, 24, 29, and 31 January 2003. Values were obtained using the procedure described in Sect. 4 and illustrated in Fig. 10.

channel widths, we have performed other calculations that do account for these variations and found that transmissions calculated by the two methods differ by less than $1 \%$. These more detailed calculations use the Kurucz (1995) solar spectrum, absorbing gas spectra from MODTRAN (Kneizys et al., 1996), the Rayleigh scattering results of Bucholtz et al. (1995), and aerosol extinction spectra typical of those in Figs. 8, 10-12, and 15. The reason for the small differences is the limited variation within each AATS channel of the optical depths $O D_{i}(\lambda)$ for the constituents relevant to this paper. These same comparisons also show that Eqs. (1)(6), which are exact for monochromatic radiation, also apply with similar accuracy to the AATS channels used, and the constituents addressed, in this paper-despite the solar fine structure within each channel.

The curves in Fig. 10 are drawn to guide the eye. Those for the absorbing gases $\left(\mathrm{O}_{3}, \mathrm{NO}_{2}, \mathrm{O}_{2}-\mathrm{O}_{2}\right)$ were adapted from results of the Moderate Resolution Transmission (MODTRAN) Code (Kneizys et al., 1996) using a view path from $10.4 \mathrm{~km}$ to space at a solar zenith angle of $90^{\circ}$ and a FWHM of $50 \mathrm{~cm}^{-1}$. (This FWHM in wavenumber corresponds to a FWHM in wavelength of 0.614 to $12.8 \mathrm{~nm}$ over the wavelength range $350-1600 \mathrm{~nm}$. The wavenumber increment of the MODTRAN calculations is $1 \mathrm{~cm}^{-1}$, or 0.01225 to $0.256 \mathrm{~nm}$ in wavelength). The symbols for the absorbing gas results in Fig. 10 do not fall exactly on the curves because 
of the different methods used to calculate symbol and curve positions. That is, the symbol positions are calculated using AATS-14 filter functions with LBLRTM, HITRAN, etc. (details above), whereas the curves use MODTRAN with a FWHM fixed in wavenumber but varying in wavelength. Despite these differences, we feel that the curves help to illustrate the physics behind the symbol positions. We emphasize that it is the symbols that give the values used for each AATS14 channel when converting from $S Z A_{\text {meas }}$ to $90^{\circ}$ and when deriving aerosol LOS OT and $O D$.

We have excluded from Fig. 10 the AATS-14 channel at $941 \mathrm{~nm}$, which is strongly affected by water vapor absorption and in fact used to retrieve water vapor (e.g., Schmid et al., 1996, 2001). The other AATS-14 channels shown in Fig. 10 are only weakly affected by water vapor absorption, and so the analyses shown here do not account for water vapor effects (though our traditional analyses do - see, e.g., Schmid et al., 1996, 2001).

The curves for aerosol $O D$ and $L O S O T$ in Fig. 10 are fits of the form

$\log O D_{\mathrm{a}}=\mathrm{c}_{0}+\mathrm{c}_{1} \log \lambda+\mathrm{c}_{2}(\log \lambda)^{2}$,

where the $\mathrm{c}_{\mathrm{i}}$ are fitting coefficients (see also Livingston et al., 2005). As with the absorbing gas curves, they are drawn to guide the eye, and are not used in deriving aerosol $O D$ and LOSOT at AATS-14 wavelengths. Aerosol LOSOT and OD are derived at each AATS-14 channel wavelength by using Eqs. (5) and (6) above.

Curves for total $O D$ and total $L O S O T$ in Fig. 10 were obtained by adding curves for components. Curves for total transmission $T$ were obtained by multiplying curves for components, as in Eq. (1).

Vertical profile inputs used to get $m_{i}$ in Fig. 6 (hence Fig. 10) were obtained as follows (see also Sect. 2):

- Rayleigh: The MODTRAN subarctic winter molecular density model.

- $\mathrm{NO}_{2}$ : Same as ozone (see below).

- Ozone: The SAGE III or POAM III profile closest to the DC-8. (If a profile did not extend down to the DC-8 altitude, it was extended using the ozone concentration measured on the DC-8.)

- $\mathrm{O}_{2}-\mathrm{O}_{2}$ : Same as Rayleigh.

- Aerosol: SAGE III aerosol extinction profiles at wavelength $755 \mathrm{~nm}$ (Fig. 2. Changes in SAGE III data versions affect extinction profile shapes, and therefore airmass values. However, the change from SAGE III v2.00 to v3.00 affected aerosol airmass by $<2 \%$.)

Notice in Fig. 10 (middle frame) that converting from $S Z A_{\text {meas }}$ to $90^{\circ}$ shifts ozone LOSOT results less than Rayleigh and aerosol LOSOT. This is explained by Eq. (4) along with the facts that $\Delta \mathrm{m}_{O 3}<\Delta \mathrm{m}_{R}$ and $\Delta \mathrm{m}_{O 3}<\Delta \mathrm{m}_{a}$, where $\Delta \mathrm{m}_{i}=\mathrm{m}_{i}\left(90^{\circ}\right)-\mathrm{m}_{i}\left(S Z A_{\text {meas }}\right)$. The relevant values of $\mathrm{m}_{i}$ are shown in, e.g., Figs. 4 and 6. As mentioned in Sect. 2, the reason that $m_{O 3}<m_{R}$ and $m_{O 3}<m_{a}$ is that most ozone extinction was farther from the DC-8 than most Rayleigh and aerosol extinction.

\subsection{Transmission-derived AATS-SAGE comparison results}

Figure 11 shows, for 19 January at $10.43 \mathrm{~km}$, the SAGE archived values for total transmission $T$ (which were previously shown at selected wavelengths in the top row of Fig. 9), for total LOSOT (obtained from $T$ using Eq. (5) without the subscript $i$ ), and total $O D$ (obtained using components as follows). Results for the components (aerosol, Rayleigh, $\mathrm{NO}_{2}$, ozone, $\mathrm{O}_{2}-\mathrm{O}_{2}$ ) were obtained by applying to the SAGE total transmission values the method of Sect. 3.3. That is, we used Eqs. (3) and (2) at apparent (refracted) $S Z A=90^{\circ}$, with the inputs listed in Sect. 3.3 - except that SAGE-retrieved ozone was used in place of AATS-retrieved ozone. Also, at each SAGE wavelength, we used absorbing gas cross sections computed from MODTRAN as described in Sect. 3.3. These cross sections differ somewhat from the cross sections used in the standard processing that produces the SAGE archived data products. Table 1 shows how the MODTRAN and SAGE-standard cross sections compare. Note, for example, that, at the 601-nm peak of the Chappuis ozone absorption band, the MODTRAN and SAGE-standard cross sections agree to within a few percent. Percent differences are larger at other wavelengths and for $\mathrm{NO}_{2}$. However, where cross section differences exceed $10 \%$, the cross sections themselves are relatively small, producing absorbing gas optical depths that are less than or equal to aerosol optical depth $(A O D)$. This can be seen by comparing the entries in Table 1 with the optical depths shown in Fig. 11. Hence, these cross section differences would impact the SAGE $A O D$ values we derive by $10 \%$ or less.

To facilitate AATS-SAGE comparisons, we also show in Fig. 11 the AATS results, for components and totals, at apparent $S Z A=90^{\circ}$, previously shown in Fig. 10.

This same transmission-oriented analysis was applied to the AATS-SAGE near-coincidences on 24, 29, and 31 January 2003. Resulting AATS-SAGE comparisons, in terms of vertical $O D$ (total and components) are shown in Fig. 12, along with the results for 19 January.

For ease of comparison we also repeat in Fig. 8 the transmission-derived $A O D$ s from both AATS and SAGE. Comparing the AATS transmission-derived and conventionally derived $A O D$ s shows them to be identical for $\lambda>600 \mathrm{~nm}$, and to differ by less than a few $\%$ for $\lambda<600 \mathrm{~nm}$. The reason for the differences in AATS AODs at short wavelengths is the assumed $\mathrm{NO}_{2}$ column values, which are $2 \times 10^{15} \mathrm{~cm}^{-2}$ on all days for the AATS conventional analyses but set equal to the SAGE retrieved value above the DC- 8 altitude for the transmission-oriented analyses. (The SAGE retrieved values, shown in Fig. 12 are 0.75, 1.32, 1.33, and 1.81, all 
Table 1. Comparison of MODTRAN-calculated cross sections with those used in SAGE III standard analyses.

\begin{tabular}{ccccc}
\hline \multicolumn{2}{c}{ WAVELENGTH $[\mathrm{nm}]$} & \multicolumn{2}{c}{$\mathrm{O}_{3}$ CROSS SECTION $\left[\mathrm{cm}^{2} / \mathrm{molec}\right]$} & RATIO \\
\hline SAGE III & MODTRAN & SAGE III & MODTRAN & SAGE/MODTRAN \\
\hline 448.518 & 448.511 & $1.138 \mathrm{E}-22$ & $1.170 \mathrm{E}-22$ & 0.97 \\
520.312 & 520.318 & $1.724 \mathrm{E}-21$ & $1.774 \mathrm{E}-21$ & 0.97 \\
601.237 & 601.251 & $5.118 \mathrm{E}-21$ & $5.175 \mathrm{E}-21$ & 0.99 \\
675.575 & 675.584 & $1.498 \mathrm{E}-21$ & $1.448 \mathrm{E}-21$ & 1.03 \\
755.378 & 755.401 & $3.166 \mathrm{E}-22$ & $2.876 \mathrm{E}-22$ & 1.10 \\
869.331 & 869.338 & $5.658 \mathrm{E}-23$ & $5.172 \mathrm{E}-23$ & \multirow{2}{*}{ RATIO } \\
\hline WAVELENGTH [nm] & NO 2 CROSS SECTION [cm $2 / \mathrm{molec}]$ & SAGE/MODTRAN \\
\hline SAGE III & MODTRAN & SAGE III & MODTRAN & 0.98 \\
\hline 384.269 & 384.275 & $5.830 \mathrm{E}-19$ & $5.957 \mathrm{E}-19$ & 0.78 \\
448.518 & 448.511 & $5.202 \mathrm{E}-19$ & $6.705 \mathrm{E}-19$ & 0.74 \\
520.312 & 520.318 & $1.408 \mathrm{E}-19$ & $1.905 \mathrm{E}-19$ & 0.93 \\
601.237 & 601.251 & $3.774 \mathrm{E}-20$ & $4.071 \mathrm{E}-20$ & 1.00 \\
\hline 675.575 & 675.584 & $8.391 \mathrm{E}-21$ & $8.414 \mathrm{E}-21$ & \\
\hline
\end{tabular}

All cross sections calculated for $220 \mathrm{~K}$

SAGE III: wavelength is mean value for pixel group; cross section is for coadded pixels within group MODTRAN: single wavelength and cross section closest to SAGE III pixel group center wavelength

$\times 10^{15} \mathrm{~cm}^{-2}$, on $19,24,29$, and 31 January 2003 , respectively.)

Comparing the SAGE transmission-derived and conventionally derived $A O D$ s in Fig. 8 shows them to be quite similar, with fitted $A O D$ curves differing by $10 \%$ or less. One source of the SAGE AOD differences is the different cross sections assumed for absorbing gases, discussed in conjunction with Table 1.

The important point is that the AATS-SAGE $A O D$ differences obtained from conventional analyses persist in the transmission-oriented analyses, being reduced only slightly if at all at most wavelengths for each case. That is, the transmission-oriented analysis does not explain the bulk of the $A O D$ differences found in the conventional analysis. This result is consistent with the AATS-SAGE transmission comparison shown in Fig. 9. That is, the AATS-SAGE differences are evident in the transmissions, even before the analysis for $A O D$ is conducted. Using Eq. (5) without the subscript $i$, yields the conversion between transmission differences and total LOSOT differences, namely

$$
\frac{d L O S O T}{L O S O T}=\frac{-1}{\operatorname{LOSOT}} \frac{d T}{T}
$$

Since total LOSOT tends to decrease with increasing wavelength (because of the Rayleigh $\lambda^{-4}$ dependence), increasing wavelength tends to amplify a given relative transmission difference, $d T / T$, when converting to $d L O S O T / L O S O T$. These differences are discussed more fully in the following subsection.

\subsection{Discussion of AATS-SAGE comparisons}

Table 2 lists differences between AATS and SAGE results for the four AATS-SAGE comparison cases shown in Figs. 9 and 11-12 (i.e., the transmission-oriented comparisons). These comparisons have several features in common:

- SAGE and AATS LOS total transmissions $T$ (both at apparent $S Z A=90^{\circ}$ ) agree to within $28 \%$ at all wavelengths $\lambda$ 450-1545 m (Table 2a). Mean and root-mean-square (RMS) differences, (SAGE-AATS)/AATS, are $\leq 20 \%$ at each $\lambda$.

- Because of Eq. (8), the relatively weak wavelength dependence of the AATS-SAGE relative transmission differences $d T / T$ corresponds to a stronger wavelength dependence of the relative difference in total LOSOT, $d L O S O T / L O S O T$. Specifically, SAGE and AATS total LOSOT values (both at apparent $S Z A=90^{\circ}$ ) agree to within $10 \%$ of the AATS value for $\lambda<\sim 755 \mathrm{~nm}$ but differ by as much as $41 \%$ of the AATS value at $1020 \mathrm{~nm}$ and $62 \%$ at $1545 \mathrm{~nm}$ (Table 2c). For nearly all cases and $\lambda$, AATS total LOSOT $>$ SAGE total LOSOT. RMS differences, (SAGE-AATS)/AATS, are between 2\% and $8 \%$ for $\lambda<\sim 755 \mathrm{~nm}$ but increase to $39 \%$ at $1020 \mathrm{~nm}$, and $58 \%$ at $1545 \mathrm{~nm}$. Mean differences have similar magnitude but opposite sign.

- SAGE and AATS total vertical $O D$ values have nearly the same percentage differences as reported in the above bullet for total LOSOT (cf. Tables 1c and 1e). OD 
Table 2. AATS-SAGE differences from transmission-oriented analyses.

\begin{tabular}{|c|c|c|c|c|c|c|c|c|c|c|c|c|c|c|c|c|c|}
\hline \multicolumn{9}{|c|}{ (a) LOS total Transmission (full limb) } & \multicolumn{9}{|c|}{ (b) LOS Aerosol Transmission (full limb) } \\
\hline \multicolumn{9}{|c|}{$\%$ difference, (SAGE-AATS)/AATS } & \multicolumn{9}{|c|}{$\%$ difference, (SAGE-AATS)/AATS } \\
\hline \multicolumn{9}{|c|}{ Wavelength $(\mathrm{nm})^{*}$} & \multicolumn{9}{|c|}{ Wavelength $(\mathrm{nm})^{*}$} \\
\hline $\begin{array}{l}\text { Date, } \\
2003\end{array}$ & 448.5 & 520.3 & 601.2 & 675.6 & 755.4 & 869.3 & 1019.3 & 1545.2 & $\begin{array}{l}\text { Date, } \\
2003\end{array}$ & 448.5 & 520.3 & 601.2 & 675.6 & 755.4 & 869.3 & 1019.3 & 1545.2 \\
\hline $19 \mathrm{Jan}$. & 2.0 & 6.8 & -8.1 & 4.7 & 2.3 & 11.9 & 13.6 & 10.1 & 19 Jan. & 12.0 & 12.7 & 17.0 & 9.2 & 8.6 & 10.4 & 13.6 & 10.2 \\
\hline 24 Jan. & 17.9 & 24.2 & 12.3 & 17.5 & 8.8 & 18.8 & 19.6 & 15.3 & 24 Jan. & 30.1 & 24.9 & 25.4 & 17.3 & 15.0 & 16.5 & 19.6 & 15.4 \\
\hline 29 Jan. & 6.6 & 20.4 & 27.3 & 20.2 & 9.4 & 18.6 & 19.5 & 16.8 & 29 Jan. & 16.0 & 13.7 & 17.2 & 13.8 & 13.7 & 16.2 & 19.5 & 16.9 \\
\hline 31 Jan. & 5.2 & 16.5 & 12.6 & 18.1 & 9.0 & 21.7 & 23.5 & 19.4 & 31 Jan. & 17.2 & 12.6 & 12.6 & 14.8 & 15.4 & 19.4 & 23.4 & 19.5 \\
\hline mean & 7.9 & 17.0 & 11.0 & 15.1 & 7.4 & 17.8 & 19.0 & 15.4 & mean & 18.8 & 15.9 & 18.1 & 13.8 & 13.2 & 15.6 & 19.0 & 15.5 \\
\hline rms** & 9.9 & 18.2 & 16.7 & 16.3 & 7.9 & 18.1 & 19.4 & 15.8 & $\mathrm{rms}^{* * *}$ & 20.0 & 16.8 & 18.6 & 14.1 & 13.5 & 16.0 & 19.3 & 15.9 \\
\hline
\end{tabular}

\begin{tabular}{|c|c|c|c|c|c|c|c|c|c|c|c|c|c|c|c|c|c|}
\hline \multicolumn{9}{|c|}{ (c) LOS total optical thickness (full limb) } & \multicolumn{9}{|c|}{ (d) LOS aerosol optical thickness (full limb) } \\
\hline \multicolumn{9}{|c|}{$\%$ difference, (SAGE-AATS)/AATS } & \multicolumn{9}{|c|}{$\%$ difference, (SAGE-AATS)/AATS } \\
\hline \multicolumn{9}{|c|}{ Wavelength $(\mathrm{nm})^{*}$} & \multicolumn{9}{|c|}{ Wavelength $(\mathrm{nm})^{*}$} \\
\hline $\begin{array}{l}\text { Date, } \\
2003\end{array}$ & 448.5 & 520.3 & 601.2 & 675.6 & 755.4 & 869.3 & 1019.3 & 1545.2 & $\begin{array}{l}\text { Date, } \\
2003\end{array}$ & 448.5 & 520.3 & 601.2 & 675.6 & 755.4 & 869.3 & 1019.3 & 1545.2 \\
\hline $\begin{array}{l}19 \text { Jan. } \\
24 \text { Jan. } \\
29 \text { Jan. } \\
\text { 31 Jan. }\end{array}$ & $\begin{array}{l}-0.4 \\
-3.2 \\
-1.4 \\
-0.9\end{array}$ & $\begin{array}{l}-2.0 \\
-5.6 \\
-5.1 \\
-3.8\end{array}$ & $\begin{array}{r}2.5 \\
-2.7 \\
-5.8 \\
-3.0\end{array}$ & $\begin{array}{l}-2.9 \\
-8.3 \\
-9.9 \\
-8.6\end{array}$ & $\begin{array}{l}-2.7 \\
-8.4 \\
-9.5 \\
-8.2\end{array}$ & $\begin{array}{l}-20.2 \\
-26.1 \\
-27.6 \\
-27.0\end{array}$ & $\begin{array}{l}-33.2 \\
-39.0 \\
-41.1 \\
-40.9\end{array}$ & $\begin{array}{l}-49.8 \\
-57.4 \\
-62.1 \\
-60.8\end{array}$ & $\begin{array}{l}19 \text { Jan. } \\
24 \text { Jan. } \\
29 \text { Jan. } \\
\text { 31 Jan. }\end{array}$ & $\begin{array}{l}-16.0 \\
-32.3 \\
-19.0 \\
-18.0\end{array}$ & $\begin{array}{l}-21.2 \\
-33.6 \\
-20.3 \\
-16.6\end{array}$ & $\begin{array}{l}-34.7 \\
-41.2 \\
-30.5 \\
-20.3\end{array}$ & $\begin{array}{l}-25.2 \\
-36.8 \\
-31.3 \\
-29.0\end{array}$ & $\begin{array}{l}-26.2 \\
-36.0 \\
-34.6 \\
-33.4\end{array}$ & $\begin{array}{l}-38.5 \\
-47.8 \\
-48.6 \\
-48.8\end{array}$ & $\begin{array}{l}-53.3 \\
-59.9 \\
-61.7 \\
-62.2\end{array}$ & $\begin{array}{l}-58.0 \\
-65.2 \\
-69.6 \\
-68.5\end{array}$ \\
\hline $\begin{array}{l}\text { mean } \\
\text { rms** }\end{array}$ & $\begin{array}{r}-1.5 \\
1.8\end{array}$ & $\begin{array}{r}-4.1 \\
4.3\end{array}$ & $\begin{array}{r}-2.3 \\
3.8\end{array}$ & $\begin{array}{r}-7.4 \\
7.9\end{array}$ & $\begin{array}{r}-7.2 \\
7.7\end{array}$ & $\begin{array}{r}-25.2 \\
25.4\end{array}$ & $\begin{array}{r}-38.5 \\
38.7\end{array}$ & $\begin{array}{r}-57.5 \\
57.7\end{array}$ & $\begin{array}{l}\text { mean } \\
\mathrm{rms}^{* *}\end{array}$ & $\begin{array}{r}-21.3 \\
22.3\end{array}$ & $\begin{array}{r}-23.0 \\
23.8\end{array}$ & $\begin{array}{r}-31.7 \\
32.6\end{array}$ & $\begin{array}{r}-30.6 \\
30.9\end{array}$ & $\begin{array}{r}-32.5 \\
32.8\end{array}$ & $\begin{array}{r}-45.9 \\
46.1\end{array}$ & $\begin{array}{r}-59.3 \\
59.4\end{array}$ & $\begin{array}{r}-65.3 \\
65.5\end{array}$ \\
\hline
\end{tabular}

\begin{tabular}{|c|c|c|c|c|c|c|c|c|c|c|c|c|c|c|c|c|c|}
\hline \multicolumn{9}{|c|}{ (e) Total vertical optical depth } & \multicolumn{9}{|c|}{ (f) Aerosol vertical optical depth } \\
\hline \multicolumn{9}{|c|}{$\%$ difference, (SAGE-AATS)/AATS } & \multicolumn{9}{|c|}{$\%$ difference, (SAGE-AATS)/AATS } \\
\hline \multicolumn{9}{|c|}{ Wavelength $(\mathrm{nm})^{*}$} & \multicolumn{9}{|c|}{ Wavelength $(\mathrm{nm})^{*}$} \\
\hline $\begin{array}{l}\text { Date, } \\
2003\end{array}$ & 448.5 & 520.3 & 601.2 & 675.6 & 755.4 & 869.3 & 1019.3 & 1545.2 & $\begin{array}{l}\text { Date, } \\
2003\end{array}$ & 448.5 & 520.3 & 601.2 & 675.6 & 755.4 & 869.3 & 1019.3 & 1545.2 \\
\hline 19 Jan. & -0.4 & -0.6 & 4.9 & -1.0 & -2.1 & -20.5 & -33.1 & -49.9 & 19 Jan. & -16.0 & -21.2 & -34.7 & -25.2 & -26.2 & -38.5 & -53.3 & -58.0 \\
\hline 24 Jan. & -3.7 & -4.6 & -1.0 & -6.8 & -8.8 & -27.6 & -40.3 & -58.1 & $24 \mathrm{Jan}$. & -32.3 & -33.6 & -41.2 & -36.8 & -36.0 & -47.8 & -59.9 & -65.2 \\
\hline $29 \mathrm{Jan}$. & -1.2 & -4.8 & -5.1 & -8.9 & -8.5 & -26.9 & -39.3 & -61.3 & $29 \mathrm{Jan}$. & -19.0 & -20.3 & -30.5 & -31.3 & -34.6 & -48.6 & -61.7 & -69.6 \\
\hline $31 \mathrm{Jan}$. & -0.9 & -3.5 & -2.5 & -7.6 & -7.7 & -26.9 & -40.2 & -60.5 & 31 Jan. & -18.0 & -16.6 & -20.3 & -29.0 & -33.4 & -48.8 & -62.2 & -68.5 \\
\hline mean & -1.6 & -3.4 & -0.9 & -6.1 & -6.8 & -25.5 & -38.2 & -57.5 & mean & -21.3 & -23.0 & -31.7 & -30.6 & -32.5 & -45.9 & -59.3 & -65.3 \\
\hline $\mathrm{rms}^{* *}$ & 2.0 & 3.8 & 3.8 & 6.8 & 7.3 & 25.6 & 38.3 & 57.6 & $\mathrm{rms}^{* *}$ & 22.3 & 23.8 & 32.6 & 30.9 & 32.8 & 46.1 & 59.4 & 65.5 \\
\hline
\end{tabular}

\begin{tabular}{|c|c|c|c|c|c|c|c|c|c|c|c|c|c|c|c|c|c|}
\hline \multicolumn{9}{|c|}{ (g) Total vertical optical depth } & \multicolumn{9}{|c|}{ (h) Aerosol vertical optical depth } \\
\hline \multicolumn{9}{|c|}{ Difference, (SAGE-AATS) } & \multicolumn{9}{|c|}{ Difference, (SAGE-AATS) } \\
\hline \multicolumn{9}{|c|}{ Wavelength $(\mathrm{nm})^{*}$} & \multicolumn{9}{|c|}{ Wavelength $(\mathrm{nm})^{*}$} \\
\hline $\begin{array}{l}\text { Date, } \\
2003\end{array}$ & 448.5 & 520.3 & 601.2 & 675.6 & 755.4 & 869.3 & 1019.3 & 1545.2 & $\begin{array}{l}\text { Date, } \\
2003\end{array}$ & 448.5 & 520.3 & 601.2 & 675.6 & 755.4 & 869.3 & 1019.3 & 1545.2 \\
\hline 19 Jan. & -0.0002 & -0.0003 & 0.0027 & -0.0002 & -0.0002 & -0.0014 & -0.0015 & -0.0012 & $19 \mathrm{Jan}$. & -0.0014 & -0.0015 & -0.0019 & -0.0011 & -0.0010 & -0.0012 & -0.0016 & -0.0012 \\
\hline $24 \mathrm{Jan}$. & -0.0024 & -0.0027 & -0.0008 & -0.0022 & -0.0013 & -0.0024 & -0.0024 & -0.0019 & 24 Jan. & -0.0035 & -0.0030 & -0.0030 & -0.0022 & -0.0019 & -0.0021 & -0.0024 & -0.0019 \\
\hline $29 \mathrm{Jan}$. & -0.0007 & -0.0024 & -0.0036 & -0.0025 & -0.0010 & -0.0020 & -0.0019 & -0.0017 & $29 \mathrm{Jan}$. & -0.0016 & -0.0014 & -0.0017 & -0.0014 & -0.0014 & -0.0016 & -0.0019 & -0.0017 \\
\hline 31 Jan. & -0.0006 & -0.0019 & -0.0017 & -0.0022 & -0.0011 & -0.0024 & -0.0024 & -0.0021 & 31 Jan. & -0.0018 & -0.0014 & -0.0014 & -0.0016 & -0.0017 & -0.0021 & -0.0024 & -0.0021 \\
\hline mean & -0.0010 & -0.0018 & -0.0009 & -0.0018 & -0.0009 & -0.0021 & -0.0021 & -0.0017 & mean & -0.0021 & -0.0018 & -0.0020 & -0.0016 & -0.0015 & -0.0018 & -0.0021 & -0.0017 \\
\hline $\mathrm{rms}^{* *}$ & 0.0013 & 0.0020 & 0.0024 & 0.0020 & 0.0010 & 0.0021 & 0.0021 & 0.0018 & $\mathrm{rms}^{* *}$ & 0.0022 & 0.0019 & 0.0021 & 0.0016 & 0.0015 & 0.0018 & 0.0021 & 0.0018 \\
\hline
\end{tabular}

* Wavelengths shown are SAGE III aerosol-archive wavelengths, except that $1019.3 \mathrm{~nm}$ (SAGE III transmission Pixel Group 81) is shown in place of $1021.6 \mathrm{~nm}$ to accomodate our SAGE III transmission-derived results at wavelength $1019.3 \mathrm{~nm}$.

In calculating AATS-SAGE differences, AATS results were interpolated to SAGE wavelengths.

${ }^{* *} r m s=\sqrt{\sum_{i=1, n} x_{i}^{2} / n}$

differences themselves (SAGE minus AATS, Table 2g) are between -0.0002 and -0.0036 for $\lambda<\sim 755 \mathrm{~nm}$ and between -0.0002 and -0.0019 for $\lambda>\sim 755 \mathrm{~nm}$. RMS differences are between 0.0013 and 0.0024 for all wavelengths. Mean differences have slightly smaller magnitude and opposite sign.

- Differences between SAGE and AATS AOD (Table 2h) are similar to differences in total $O D$. However, because $A O D$ is less than total $O D$, percentage differences for $A O D$ (Table 2f) exceed those for $O D$ (Table 2e). RMS percentage differences in $A O D$ ([SAGE minus AATS]/AATS) were $\leq 33 \%$ for $\lambda<\sim 755 \mathrm{~nm}$ but increased to $59 \%$ for $1020 \mathrm{~nm}$ and $66 \%$ at $1545 \mathrm{~nm}$ (Table 2f).

Because AATS $O D$ exceeds SAGE $O D$ for virtually all cases and wavelengths, and because the AATS entrance window developed frost on some DC-8 flights out of Kiruna prior to 19 January 2003 , it is necessary to investigate whether the 
larger AATS-retrieved $O D$ s could be caused by window frost. However, as described more fully in Appendix A, we have performed four tests for the presence of window frost in each of the cases presented here, and all tests indicated no frost. The tests and the AATS-14 design also imply no deposit on any other optical element in the instrument optical path (an interference filter and detector for each channel). These results lead us to conclude that the combined frost-prevention measures used in these cases - window heating and more extensive purging with dry nitrogen than for the early flights were successful. Additional evidence against AATS window frost or other deposits on AATS optical surfaces is provided by comparison of AATS results with those from the Directbeam Irradiance Airborne Spectrometer (DIAS), reported in Sect. 4.

In a similar fashion, differences between SAGE III and AATS $A O D$ could be attributed to SAGE III. From Fig. 9 and Table 2a, it is clear that the differences originate at the transmission level, so the clearing of molecular scatter and absorption by ozone, nitrogen dioxide, water vapor, and carbon dioxide (at $1540 \mathrm{~nm}$ only) cannot be the primary sources of the discrepancy. The most likely scenario would be a systematic error in altitude registration of the individual spectra. However, to produce the observed $A O D$ differences, the 1020-nm channel would need to be consistently located low by about $2 \mathrm{~km}$ and the $1550-\mathrm{nm}$ channel by over $5 \mathrm{~km}$. This is extremely unlikely because altitude errors of this magnitude would cause catastrophic problems in other products like ozone and short wavelength aerosol that are not observed. Also, since altitude registration is linked between channels, it is not possible for the quality of the altitude registration to vary significantly from channel to channel. Comparisons of transmission between SAGE II and SAGE III at $1020 \mathrm{~nm}$ show a difference of about $10 \%$ and are consistent with the $\sim 20 \%$ difference in aerosol extinction at this wavelength reported by Thomason and Taha (2003). Aerosol extinction spectra computed from in situ measurements made by a Focused Cavity Aerosol Spectrometer (FCAS) aboard the DC- 8 tend to agree with SAGE III aerosol extinction spectra except at $1550 \mathrm{~nm}$ where the computed extinctions are significantly less than SAGE III values (see also Taha et al., 2004). Comparisons of aerosol extinction spectra computed from the University of Wyoming Optical Particle Counter (OPC) are consistently significantly less than SAGE III values.

We note that the flatter wavelength dependence of AATSderived $A O D$ as compared to SAGE III $A O D$ implies larger particle sizes than would be derived from the SAGE III spectra. However, at DC-8 altitudes, there are several mechanisms that make larger particle sizes plausible. For example, Fahey et al. (2001) and Northway et al. (2002) report extensive measurements of large ( 5 to $>20 \mu \mathrm{m}$ diameter) nitric acid-containing particles over a large altitude range (16$21 \mathrm{~km})$ and horizontal extent $(1800 \mathrm{~km})$ in the Arctic stratosphere during several weeks of the 1999-2000 winter. They note that such particles have sedimentation speeds capable of falling out of the stratosphere (thereby denitrifying it), and that the particles are transported horizontally by winds as they sediment over periods of several days. McKinney et al. (2004) show that the observations are consistent with particle trajectory calculations that assume a composition of nitric acid trihydrate. Large ice particles associated with forming or dissipating cirrus are also not uncommon at DC-8 altitudes. And finally, as shown in Sect. 5, POAM III Version 4 data give $A O D$ spectra with slopes very similar to those found by AATS. DC- 8 in situ measurements might also be used to test for the presence of large particles at DC- 8 altitudes. Indeed, the FCAS measurements mentioned above do not show the presence of such particles. However, these measurements do not describe all the AATS-viewed path, and one must also bear in mind the difficulty of preserving all optically significant large particles when sampling through inlet and instrument systems at DC-8 speeds.

We note also that the AATS-SAGE comparisons in Figs. 8 and 11-12 approximate aerosol airmass $\mathrm{m}_{a}$ as wavelengthindependent, setting $\mathrm{m}_{a}(\lambda)=\mathrm{m}_{a}(755 \mathrm{~nm})$. A more complete (and cumbersome) treatment would use wavelengthdependent $\mathrm{m}_{a}$. As discussed in Sect. 2, using wavelengthdependent $\mathrm{m}_{a}$ would decrease AATS-retrieved $A O D$ at $\lambda>755 \mathrm{~nm}$ and increase it at $\lambda<755 \mathrm{~nm}$. The size of the changes can be estimated from Fig. 5, which shows that, for DC-8 altitude $10.5 \mathrm{~km}$, maximum differences at the shortest available SAGE wavelength, $449 \mathrm{~nm}$, i.e., $\left[\mathrm{m}_{a}(449 \mathrm{~nm})-\mathrm{m}_{a}(755 \mathrm{~nm})\right] / \mathrm{m}_{a}(755 \mathrm{~nm})$ are $14 \%$ for true $S Z A_{\text {meas }}=90^{\circ}$, $8 \%$ for $S Z A_{\text {meas }}=89^{\circ}$ and less for smaller $S Z A_{\text {meas }}$. Differences for the longest SAGE wavelength, $1550 \mathrm{~nm}$, are similar (with opposite sign), because, as noted in Sect. 2 and shown in Fig. $5, \mathrm{~m}_{a}(755 \mathrm{~nm})$ is very close to the mean of $\mathrm{m}_{a}(449 \mathrm{~nm})$ and $\mathrm{m}_{a}(1550 \mathrm{~nm})$. Thus the changes in AATS AOD that would result from using wavelengthdependent $\mathrm{m}_{a}$ are too small to explain the longer-wavelength AATS-SAGE $A O D$ differences in Figs. 8 and 11-12 and in Table 2f, which are mostly $>\sim 50 \%$ of AATS AOD at $1020 \mathrm{~nm}$ and $>\sim 60 \%$ at $1545 \mathrm{~nm}$.

\section{DIAS-AATS Comparisons}

The NCAR Direct-beam Irradiance Airborne Spectrometer (DIAS) flew on-board the DC-8 with AATS-14 and measured direct solar UV and visible irradiance from 290 to $630 \mathrm{~nm}$. DIAS achieves a resolution of roughly $1 \mathrm{~nm}$ (comparable to SAGE III) by using a scanning double monochromator detection system, based on an instrument used by Shetter and Müller (1999). The DIAS optical collector viewed the Sun through a fused silica optical window mounted on the left side of the DC-8 cabin. Yee et al. (2004) and Swartz et al. (2005) have used the DIAS data $(320-630 \mathrm{~nm})$ to derive total LOSOT, as well as the individual ozone, aerosol, and $\mathrm{O}_{2}-\mathrm{O}_{2}$ LOSOT. They do not attempt to infer vertical column amounts, and focus entirely on the LOS path, because 
inference of vertical columns requires additional assumptions and leads to more uncertainty (cf. Sect. 2).

The middle frame of Fig. 10 includes an example DIAS result, the aerosol LOSOT at $\lambda=400 \mathrm{~nm}$ on 19 January at $10.48-$ $10.80 \mathrm{UT}$, shown in comparison to the AATS result for the partially overlapping period $10.32-10.62$ UT. The DIAS and AATS values are 0.68 and 0.67 , respectively (both doubled to convert from the DC-8-viewed half limb to a symmetrical full limb), thus agreeing to within $2 \%$. For the fully overlapping time period 10.48-10.62 UT the DIAS and AATS full-limb values are 0.68 and 0.71 , respectively, agreeing to 4\% (Table 3, 19 January, 10.48-10.62 UT).

Figure 13 shows DIAS LOS aerosol optical thickness (AOT) at $S Z A_{\text {meas }}$ compared to AATS LOS AOT at $S Z A_{\text {meas }}$ for 19, 24, 29, and 31 January 2003. The AATS-DIAS differences for these days and two others (21 January and 2 February) are listed in Table 3. For all 6 days, AATS-DIAS differences in LOS AOT at $400 \mathrm{~nm}$ and SZAmeas were $\leq 12 \%$. The mean difference was $<3 \%$, and RMS difference $<8 \%$. These differences are much less than the SAGE-AATS LOS AOT differences reported in Table $2 \mathrm{~d}$, which had mean and RMS values of $-21 \%$ and $22 \%$, respectively, at the shortest available wavelength, $449.9 \mathrm{~nm}$.

The good agreement between DIAS and AATS reported above is especially significant since DIAS, located within the DC-8 cabin, viewed the sun through an optical window that was continuously viewed by on-board experimenters and showed no evidence of frost. Thus this good AATS-DIAS agreement provides additional evidence that the AATS window was frost-free during the measurements reported here. (See also Appendix A.)

\section{AATS-POAM comparisons}

\subsection{AATS-POAM comparison results}

As shown in Fig. 1, the DC-8 flew near one POAM occultation on 19 January 2003 and near three POAM occultations on 21 January. Figure 3 shows the POAM version 4 retrieved aerosol extinction profiles. For the 21 January POAM occultations, the top frame in Fig. 14 shows the SZAs and altitude of the DC-8, along with the distance from the DC-8 to the POAM tangent point and the AATS-retrieved AOD at two selected wavelengths. Time dependent airmasses, $m_{R}$, $m_{O 3}$, and $m_{a}$, for Rayleigh, ozone, and aerosol, respectively (obtained by applying the Yee airmass algorithm), are shown in the bottom frame. Aerosol airmass results $m_{a}$ were computed using the POAM III aerosol extinction profile at wavelength $779 \mathrm{~nm}$. Not shown for brevity are analogous results for the 19 January occultation, for which the DC-8 experienced $S Z A$ values within the range shown in Fig. 14.

Figure 15 compares the AATS and POAM AOD spectra obtained for the three periods on 19 January and the three periods on 21 January when the DC-8 was within $100 \mathrm{~km}$
Table 3. DIAS-AATS differences in LOS aerosol OT (AOT) at wavelength $400 \mathrm{~nm}$.

\begin{tabular}{|c|c|c|c|}
\hline & UT Start & UT End & $\begin{array}{r}\% \text { difference } \\
\text { (DIAS-AATS)/AATS }\end{array}$ \\
\hline 19 Jan. & 9.83 & 10.13 & 12.0 \\
\hline 19 Jan. & 10.48 & 10.62 & -4.0 \\
\hline 21 Jan. & 14.61 & 16.25 & -0.4 \\
\hline 24 Jan. & 10.60 & 10.86 & -0.2 \\
\hline 24 Jan. & 11.22 & 11.49 & 8.0 \\
\hline 29 Jan. & 10.27 & 10.43 & -7.0 \\
\hline 29 Jan. & 10.87 & 11.13 & -7.0 \\
\hline 29 Jan. & 11.48 & 11.64 & -9.0 \\
\hline 31 Jan. & 9.63 & 9.81 & -5.0 \\
\hline \multirow[t]{3}{*}{2 Feb. } & 12.46 & 12.80 & -10.0 \\
\hline & & mean & -2.3 \\
\hline & & $\mathrm{rms}^{* *}$ & 7.7 \\
\hline
\end{tabular}

of a POAM tangent point. (Note that the three such periods on 19 January were for a single POAM occultation, whereas each such period on 21 January was for a different POAM occultation.) The AATS and POAM results were obtained by conventional analyses, as defined in Sect. 3.1. That is, we obtained AATS AODs using the method described by the Appendix of Russell et al. (1993), and we obtained POAM $A O D$ s by vertically integrating the POAM aerosol extinction profiles in Fig. 3 above the DC- 8 altitude.

Notice that we have excluded the shortest POAM wavelength, $353 \mathrm{~nm}$, from the POAM AODs in Fig. 15, even though POAM retrieved $A O D$ values at this wavelength are shown extending down to DC-8 altitudes in Fig. 3. The reason for excluding POAM AODs at $353 \mathrm{~nm}$ is analogous to that for excluding SAGE III AODs at the SAGE 384-nm wavelength, i.e., at DC-8 altitudes the transmission signal is so depleted that signal-to-noise is virtually zero. This depletion leads to the erroneous values for SAGE III aerosol extinction at $384 \mathrm{~nm}$ that are quite evident in Fig. 2 below $\sim 11 \mathrm{~km}$. Corresponding errors in POAM III 353-nm extinction are not readily evident in Fig. 3, but this is a result of the fact that the POAM retrieval solves for the parameters of an assumed extinction functional form (analogous to Eq. (7)), rather than solving for aerosol extinction at each wavelength independently. In solving for fitting parameters, the POAM III retrieval weights channels by the signal-to-noise ratio, and hence the 353-nm channel has essentially zero weight below $\sim 12 \mathrm{~km}$. Therefore, POAM III retrieved extinction values at $353 \mathrm{~nm}$ and such altitudes are determined by fitting coefficients determined almost entirely by the signals in the longer-wavelength 


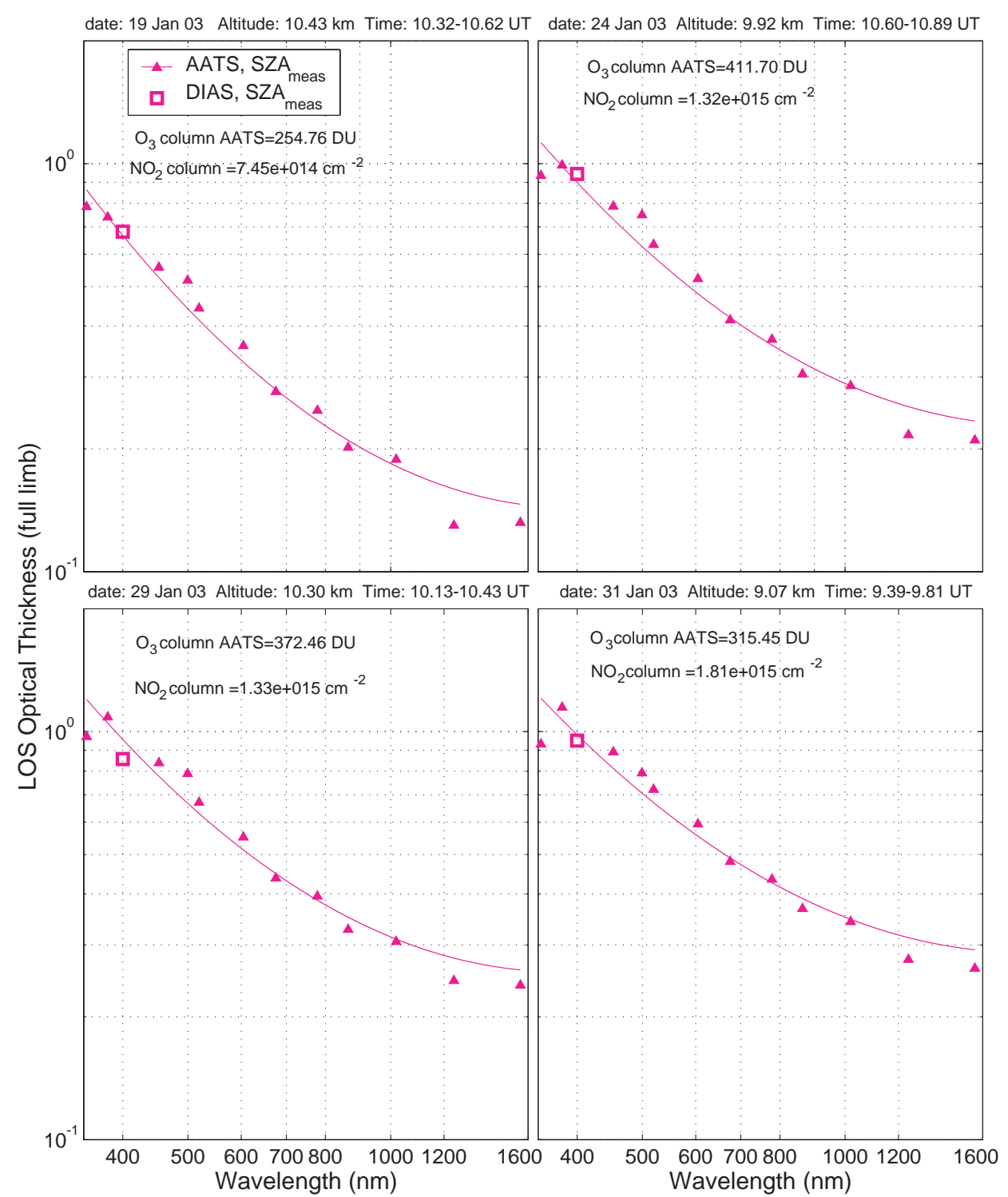

Fig. 13. DIAS LOS aerosol optical thickness (AOT) at $S Z A_{\text {meas }}$ compared to AATS LOS AOT at $S Z A_{\text {meas }}$ for 19, 24, 29, and 31 January 2003.

channels. They are therefore essentially extrapolated from those longer-wavelength channels. (Note that AATS does not have such severe signal depletion at its short wavelengths because it views through only half the limb. Hence, when SAGE and POAM short-wavelength transmissions have decreased to $\sim 10^{-4}$ at $\sim 12 \mathrm{~km}$, AATS (half-limb) transmission is $\sim 10^{-2}$ or larger. See also Sect. 3.2.)

For completeness we show in Fig. 16 vertical profiles of transmission for the four POAM occultations of Figs. 1415. Also shown are the corresponding AATS transmission values at the AATS measurement $S Z A, S Z A_{\text {meas }}$, and converted to apparent $S Z A=90^{\circ}$. Figure 16 is analogous to the SAGE-AATS transmission plot in Fig. 9. As with the SAGE-AATS comparisons, we have used the POAM-AATS transmission data to investigate the source of any POAMAATS $A O D$ differences shown in Fig. 15. In brief, the source of any such POAM-AATS AOD differences is the corresponding transmission differences, rather than differences in gas subtraction (e.g., Rayleigh, ozone, $\mathrm{NO}_{2}$ ), or factors related to airmass. This finding is similar to the result of the analogous SAGE-AATS analyses, which also found that $A O D$ differences were directly traceable to transmission differences.

\subsection{Discussion of AATS-POAM comparisons}

Table 4 lists differences between AATS and POAM results for the six AATS-POAM comparisons shown in Fig. 15. These comparisons have several features in common: 


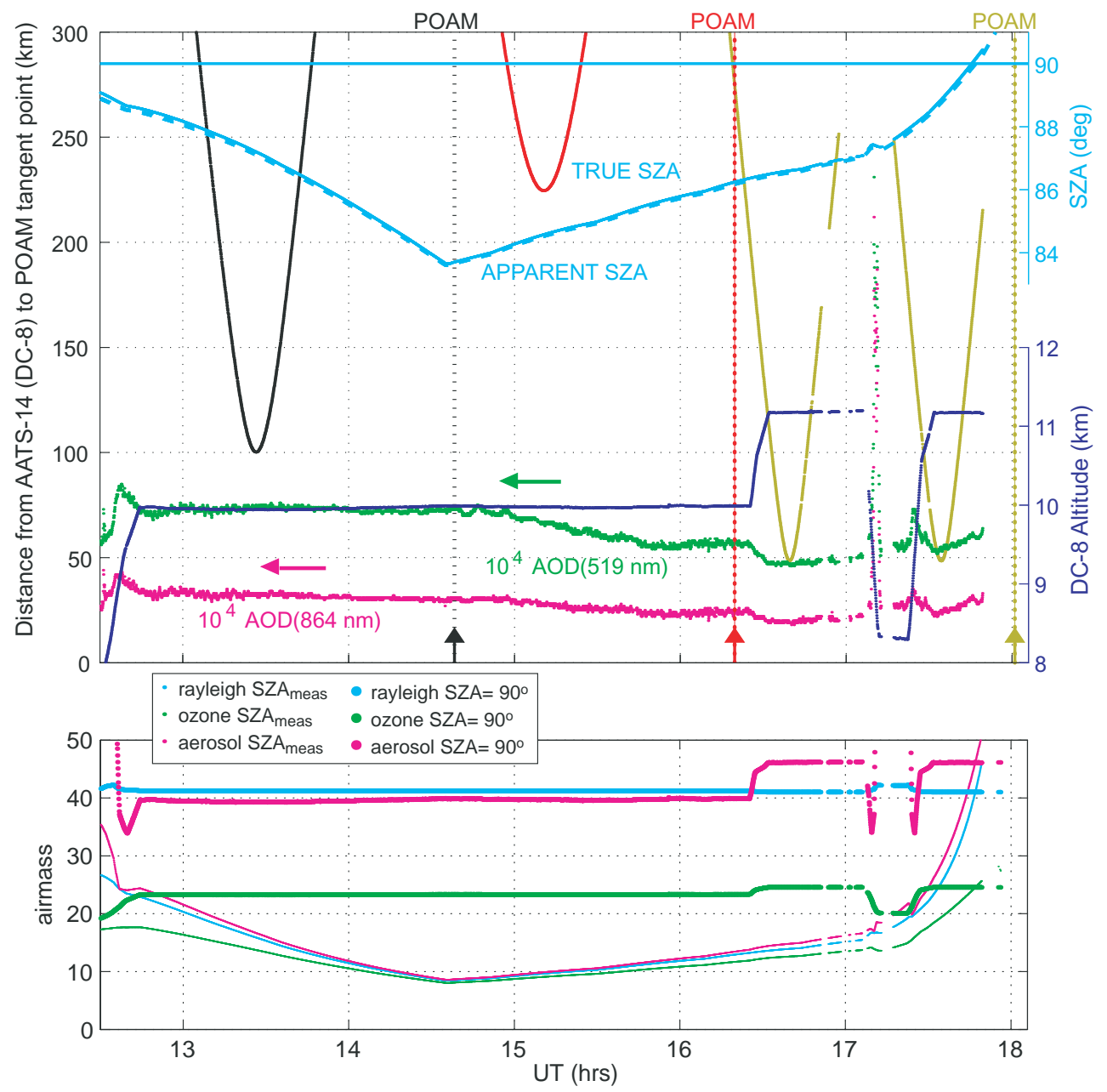

Fig. 14. Conditions and results for the DC-8 flight of 21 January 2003. Top: DC- 8 altitude, distance from POAM III 10-km tangent point, and true and apparent (refracted) $S Z A$, with $A O D$ retrieved from AATS-14 at two wavelengths. Vertical dotted lines marked by arrows and "POAM" show times of POAM III tangent at $10 \mathrm{~km}$ altitude. Bottom: Airmasses for Rayleigh, ozone, and aerosol (755 nm), at $S Z A_{m e a s}$ and apparent $S Z A=90^{\circ}$, computed from the POAM III profiles in Fig. 3 using the Yee algorithm. Results shown used POAM III version 3 profiles, but results using version 4 differ by $<6 \%$.

- RMS percentage differences in AOD ([AATSPOAM]/AATS) were $\leq 31 \%$ for all $\lambda>400 \mathrm{~nm}$ (Table 4a).

- AATS-POAM AOD differences were $\leq 0.0041$ for all $\lambda>400 \mathrm{~nm}$. RMS differences were $\leq 0.0026$. Mean differences (AATS-POAM) were $\leq 0.0015$ (Table $4 \mathrm{~b}$ ).

It is noteworthy that, at $442 \mathrm{~nm}$, the largest AATS-POAM differences occur for the 19 January POAM occultation. As shown in Fig. 3, for the 19 January occultation, POAM retrieved extinction at both 353 and $442 \mathrm{~nm}$ goes negative at altitudes 11 to $9 \mathrm{~km}$ and appears anomalously small (relative to the longest wavelengths) at $12 \mathrm{~km}$. Such behavior suggests a small altitude error in the POAM transmission profiles, which causes too much Rayleigh subtraction, affecting the short wavelength channels most noticeably. Indeed, an altitude error of $0.5 \mathrm{~km}$ or even smaller can be sufficient to cause the negative extinctions. Although POAM altitudes in general have better accuracy than this, a peak-to-peak random error of $0.5 \mathrm{~km}$ is entirely possible. Less Rayleigh subtraction would increase POAM-retrieved AOD for the 19 January occultation, reducing the AATS-POAM differences shown in Fig. 15 and Table 4.

\section{Summary and conclusions}

AATS-14 measurements on the DC-8 in SOLVE II provide $A O D$ spectra for wavelengths $354-2139 \mathrm{~nm}$, covering the full range of aerosol wavelengths for SAGE III (384-1545 nm) and POAM III $(353-1018 \mathrm{~nm})$, plus nearly all the wavelength range used in DIAS retrievals by Swartz et al. (2005, $320-630 \mathrm{~nm}$ ). In this paper we show AATS results only for 


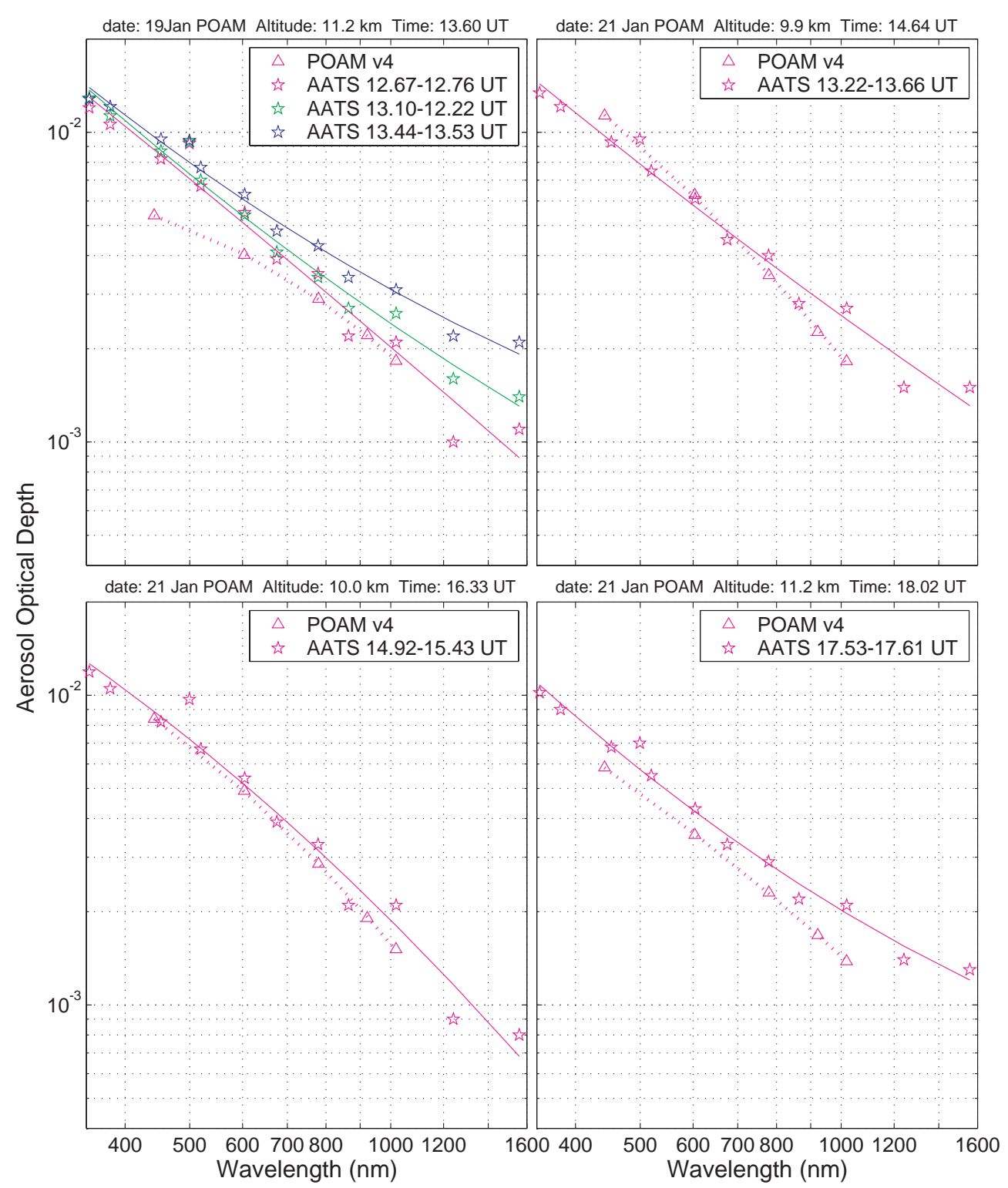

Fig. 15. Comparison of AATS-14 and POAM IIIv4 AOD spectra for the 19 and 21 January 2003 occultations shown in Figs. 3 and 14.

wavelengths $354-1558 \mathrm{~nm}$, because no correlative measurements are available at $2139 \mathrm{~nm}$. The AATS-14 results show $A O D$ spatial structure along the DC-8 flight path and provide $A O D$ spectra for comparison to SAGE III and POAM III at their tangent points, and to DIAS when it was able to view the Sun through its window on the left side of the DC-8.

In our analyses we have used a new airmass algorithm (Yee al., 2002; DeMajistre and Yee, 2002; Vervack et al., 2002), which we compared to the Thomason et al. (1983) algorithm used in our previous work. We found agreement between the two algorithms to within $2 \%$ for $S Z A<90^{\circ}$, and in addition made use of the new algorithm for conditions with $S Z A>=90^{\circ}$, which were encountered for parts of most DC-8 flights reported here.
We have compared the two DC-8 mounted instruments, AATS-14 and DIAS, in terms of results for LOS AOT at wavelength $400 \mathrm{~nm}$ and found good agreement. Specifically, for all 6 days of AATS-DIAS comparisons, differences in LOS AOT at $400 \mathrm{~nm}$ were $\leq 12 \%$. The mean difference was $<3 \%$, and RMS difference $<8 \%$. The LOS AOT differences were anticorrelated with differences between LOS Rayleigh OT used in the AATS and DIAS processing algorithms, indicating that LOS AOT differences would become even smaller if the two algorithms used a common Rayleigh OT formulation.

AATS and DIAS viewed the sun through separate windows, with the AATS window built into its externallymounted tracking head, and DIAS viewing through an 


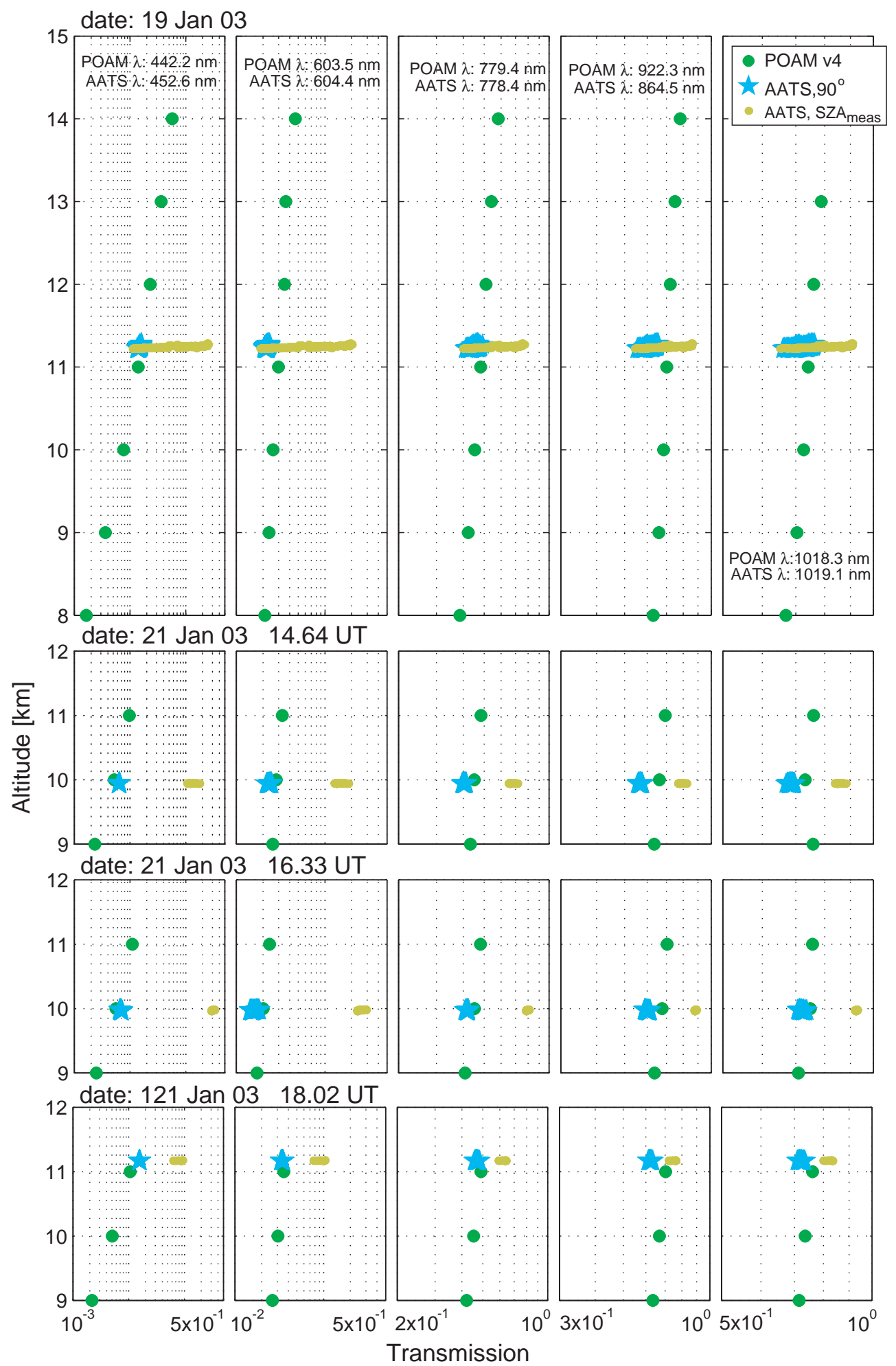

Fig. 16. POAM IIIv4 vertical profiles of transmission at representative wavelengths for the occultation events near the DC-8 on 19 and 21 January, with corresponding AATS transmission values (converted from half-limb to full limb) at the AATS measurement $S Z A, S Z A_{m e a s}$, and converted to apparent $S Z A=90^{\circ}$. 
Table 4. POAM-AATS aerosol optical depth $(A O D)$ differences.

\begin{tabular}{|c|c|c|c|c|c|c|c|c|c|}
\hline \multicolumn{10}{|c|}{ (a) $\%$ difference (POAM-AATS)/AATS } \\
\hline & & & & AATS & 452.6 & 604.4 & 778.4 & 864.5 & 1019.1 \\
\hline $\begin{array}{c}\text { Date, } \\
\text { Jan. } 2003\end{array}$ & $\begin{array}{r}\text { UT } \\
\text { start }\end{array}$ & $\begin{array}{l}\text { UT } \\
\text { end }\end{array}$ & $\begin{array}{r}\text { Alt } \\
(\mathrm{km})\end{array}$ & POAM & 442.2 & 603.5 & 779.4 & 922.3 & 1018.3 \\
\hline 19 & 12.67 & 12.76 & 11.3 & & -34 & -27 & -17 & 0 & -13 \\
\hline 19 & 13.10 & 13.22 & 11.25 & & -38 & -26 & -15 & -18 & -30 \\
\hline 19 & 13.44 & 13.53 & 11.23 & & -43 & -36 & -33 & -35 & -41 \\
\hline 21 & 13.22 & 13.66 & 9.94 & & 22 & 3 & -14 & -19 & -33 \\
\hline 21 & 14.92 & 15.43 & 9.97 & & 2 & -9 & -14 & -9 & -28 \\
\hline 21 & 17.53 & 17.61 & 11.17 & & -14 & -18 & -20 & -24 & -34 \\
\hline & & & & mean & -18 & -19 & -19 & -17 & -30 \\
\hline & & & & $\mathrm{rms}^{* *}$ & 29 & 23 & 20 & 21 & 31 \\
\hline
\end{tabular}

\begin{tabular}{|c|c|c|c|c|c|c|c|c|c|}
\hline \multicolumn{10}{|c|}{ (b) Difference (POAM-AATS) } \\
\hline & & & & AATS & 452.6 & 604.4 & 778.4 & 864.5 & 1019.1 \\
\hline $\begin{array}{c}\text { Date, } \\
\text { Jan. } 2003\end{array}$ & $\begin{array}{r}\text { UT } \\
\text { start }\end{array}$ & $\begin{array}{l}\text { UT } \\
\text { end }\end{array}$ & $\begin{array}{r}\text { Alt } \\
(\mathrm{km})\end{array}$ & POAM & 442.2 & 603.5 & 779.4 & 922.3 & 1018.3 \\
\hline 19 & 12.67 & 12.76 & 11.25 & & -0.0028 & -0.0015 & -0.0006 & 0.0000 & -0.0003 \\
\hline 19 & 13.10 & 13.22 & 11.25 & & -0.0033 & -0.0014 & -0.0005 & -0.0005 & -0.0008 \\
\hline 19 & 13.44 & 13.53 & 11.23 & & -0.0041 & -0.0023 & -0.0014 & -0.0012 & -0.0013 \\
\hline 21 & 13.22 & 13.66 & 9.94 & & 0.0020 & 0.0002 & -0.0006 & -0.0005 & -0.0009 \\
\hline 21 & 14.92 & 15.43 & 9.97 & & 0.0002 & -0.0005 & -0.0005 & -0.0002 & -0.0006 \\
\hline \multirow[t]{3}{*}{21} & 17.53 & 17.61 & 11.17 & & -0.0010 & -0.0008 & -0.0006 & -0.0005 & -0.0007 \\
\hline & & & & mean & -0.0015 & -0.0010 & -0.0007 & -0.0005 & -0.0008 \\
\hline & & & & $\mathrm{rms}^{* *}$ & 0.0026 & 0.0013 & 0.0008 & 0.0006 & 0.0008 \\
\hline
\end{tabular}

$$
{ }^{* *} r m s=\sqrt{\sum_{i=1, n} x_{i}^{2} / n}
$$

optical window mounted in a standard DC-8 window frame, where experimenters could continuously verify that no frost had formed. Therefore, a corollary of the AATS-DIAS agreement is that the AATS window was frost-free during the comparisons. This is significant, since the AATS window did develop frost in earlier DC-8 flights out of Kiruna. The AATS-DIAS indication of no frost is in accord with results from the four AATS frost tests reported in Appendix A, which also indicated no frost during the flights reported here. In combination, the five indications of no frost (the AATSDIAS comparisons and the four AATS frost tests) demonstrate the success of the two frost-prevention measures used by AATS: a window heater and stronger purging with dry nitrogen than was used in the early flights out of Kiruna.

Comparisons between AATS and the two satellite instruments, POAM III and SAGE III, yielded larger percentage differences than between the two DC-8 instruments (AATS and DIAS). For the six AATS-POAM comparisons, RMS percentage differences in $A O D$ ([AATS-POAM]/AATS) were $\leq 31 \%$ for all $\lambda, 442-1018 \mathrm{~nm}$ (Table $4 \mathrm{a}$ ). For the four AATS-SAGE comparisons, which covered a larger wavelength range, RMS percentage differences in $A O D$ ([AATSSAGE]/AATS, Table 2f) were $\leq 33 \%$ for $\lambda<\sim 755 \mathrm{~nm}$ but increased to $59 \%$ for $1020 \mathrm{~nm}$ and $66 \%$ at $1545 \mathrm{~nm}$.

To some extent, larger differences are expected in the AATS-satellite comparisons than in the AATS-DIAS comparisons. Differences in viewing path (including the major difference between full limb and half limb), in timing, and in SZA each occurred at some time for the AATS-satellite comparisons, but never for the AATS-DIAS comparisons. However, the systematic nature of the AATS-satellite differences, in which satellite $A O D$ (especially SAGE) is always less than AATS $A O D$ for $\lambda>755 \mathrm{~nm}$, suggests strongly that differences in viewing path, timing, or SZA cannot explain all 


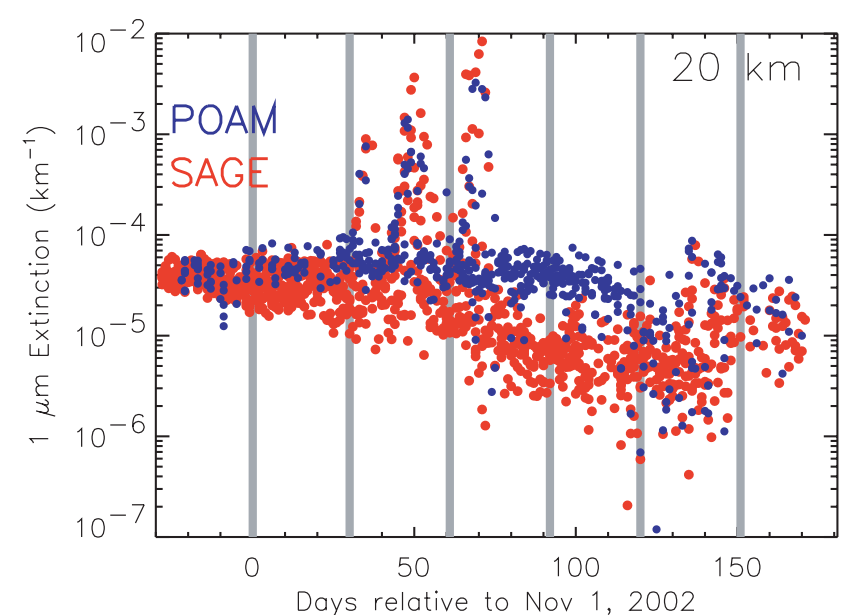

Fig. 17. Comparison of POAM IIIv4 and SAGE IIIv3.00 extinction for wavelength 1 micron and altitude $20 \mathrm{~km}$ inside the Arctic vortex, October 2002-April 2003.

the AATS-satellite differences. This prompted us to search for a systematic reason for these differences. AATS-DIAS comparisons shed little light on this search, since the longest DIAS wavelength is $630 \mathrm{~nm}$. Systematic underestimation of aerosol airmass factors in the AATS analyses could explain the larger AATS AODs, but we have to reject such airmass errors on three grounds: the airmass sensitivity study discussed in conjunction with Figs. 4-5, the success of the Yee LOS integrator (which is used by the Yee airmass algorithm) in the comparisons reported by Swartz et al. (2005), and, most of all, the fact that the AATS-satellite differences are apparent in transmissions and LOS AOTs at refracted $S Z A 90^{\circ}$, which do not depend on airmass values.

This prompted us to investigate the satellite algorithms and data sets for possible systematic errors at the time and location of the DC-8 flights (late January-February 2003, in and near the northern polar vortex). However, these investigations revealed no indications that either the POAM or the SAGE data sets has any major problems at this time and location. POAM aerosol extinction is much the same in the 2002-2003 northern winter as it is in every winter. The validation analysis for POAM v3.0 aerosols (Randall et al., 2001) revealed unexplained, but significant, systematic differences between POAM and SAGE II v6.0 aerosols. More recent comparisons between POAM v4.0 and SAGE II v6.2 aerosols indicate average agreement within $\pm 30 \%$, with no systematic biases between the instruments from $\sim 12-25 \mathrm{~km}$ (Randall et al., $2005^{1}$ ). The SAGE III results agree with the SAGE II results to $10 \%$ in transmission and $20 \%$ in AOD at $1020 \mathrm{~nm}$ for most altitudes and locations. Many in situ results also support the SAGE III results. And SAGE III altitude registration errors large enough to explain the $A O D$ differences can be rejected on several grounds reported in Sect. 3.5.

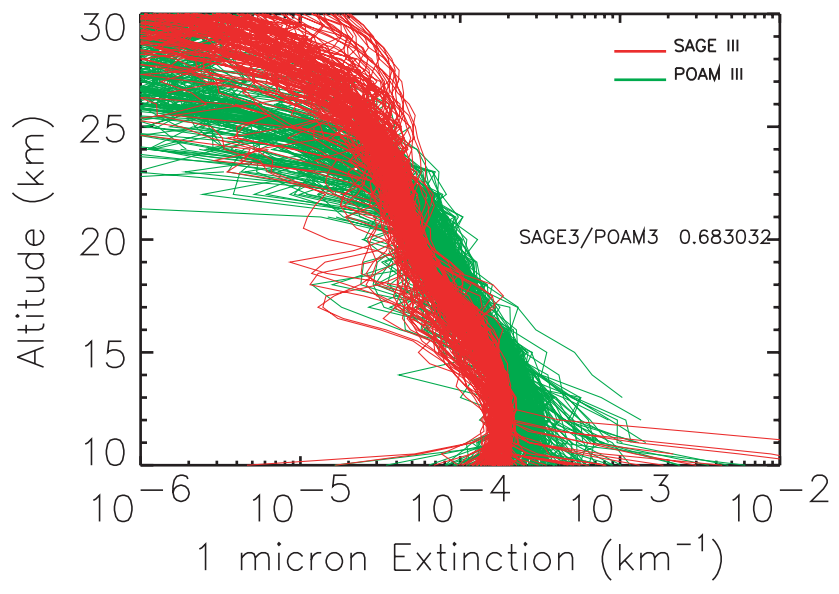

Fig. 18. Comparison of POAM IIIv4 and SAGE IIIv3.00 extinction profiles for wavelength 1 micron outside the Arctic vortex and north of $40 \mathrm{~N}$, January 2003. The ratio on the plot is the mean value at $20 \mathrm{~km}$.

Another systematic difference that bears investigation is the larger difference between SAGE and AATS than between POAM and AATS (e.g., 59\% for SAGE-AATS AOD at $1020 \mathrm{~nm}$, but $\sim 30 \%$ for POAM-AATS AOD there). This implies a systematic difference between SAGE and POAM for the time and location of the DC-8 flights. Indeed, SAGEPOAM comparisons reveal such a difference, but it is a very unusual difference in that it doesn't occur in surrounding periods. This is illustrated in Fig. 17, which shows a time series of POAM IIIv4 and SAGE IIIv3.00 aerosol extinction at $1020 \mathrm{~nm}$ and $20 \mathrm{~km}$ altitude inside the Arctic vortex during the 2002-2003 vortex season (Oct 2002-April 2003). Notice that POAM-SAGE agreement is much better at the start and end of the period than in the middle, when the AATS-satellite comparisons were made (19-31 January 2003 is day 8092 relative to 1 November 2002, the coordinate in Fig. 17). In fact, during the 19-31 January period, SAGE III aerosol extinction at $1020 \mathrm{~nm}$ and $20 \mathrm{~km}$ is often less than POAM III values by more than a factor 2. Comparisons of SAGE and POAM vertical profiles during this period show POAM $1020 \mathrm{~nm}$ extinction exceeding SAGE values from $\sim 23 \mathrm{~km}$ down to $\sim 10 \mathrm{~km}$ (see, e.g., Fig. 18, which compares SAGE III and POAM III profiles in January 2003 outside the vortex north of $40 \mathrm{~N}$ - the region of the AATS-POAM-SAGE comparisons).

Hence, the unexplained, systematic AATS-SAGE differences in $A O D$ for $\lambda>755 \mathrm{~nm}$ occurred during an unusual period when there were also unexplained, systematic SAGE IIIv3.00-POAM IIIv4 differences in aerosol extinction and $A O D$, with POAM IIIv4 systematically exceeding SAGE IIIv3.00. The fact that the comparisons reported here occurred during a time of very small stratospheric aerosol concentrations, with extinctions and $A O D$ s some of the least ever measured, also contributes to the difficulty of 
the measurements and needs to be borne in mind when assessing the differences. The analysis presented here clearly reveals that more work must be done to understand even the satellite comparisons themselves. This will require quantitative comparisons of both aerosol extinction and transmission profiles from the SAGE III, SAGE II, and POAM III instruments, and is the subject of future work. The POAMSAGE differences shown in Figs. 17 and 18, including their seasonal evolution, provide important context for the AATSPOAM and AATS-SAGE comparisons, as well as potentially important clues and a data set that can be studied in search of a resolution of the AATS-SAGE differences.

\section{Appendix A: Tests for frost on AATS-14 window or other deposits on AATS optical surfaces}

As mentioned in Sect. 3.5, the AATS-14 entrance window developed frost on some DC-8 flights out of Kiruna before 19 January 2003. The presence of frost was manifested in three ways: photographs of the window immediately after flight, scans of the AATS field of view (FOV) across the sun during flight, and erratic, elevated $O D$ spectra acquired in flight.

The entrance window photographs taken immediately after selected early flights showed irregular patches of frost that had formed on the inside surface of the window. The frost patches were located toward the middle of most of the openings in the foil heater that is mounted on the inner surface of the window. Each of these openings forms an entrance port for one of the AATS-14 channels. Different frost patches had different shapes, covering different portions of the ports and even leaving some ports frost-free. This frost formation pattern provided evidence that the water vapor source of the frost was the interior of the science detector head, that the vapor diffused from the interior toward the cold window surface, and that frost formed at the coldest points - those farthest from the foil heater hole edges. Different frost patch shapes indicate different degrees of thermal contact between the foil heater and the window surface, plus possibly different vapor availability in different detector channels.

Figure A1 shows FOV scans that support the above deductions. FOV scans are made by moving the pointing direction of AATS-14 across the Sun. We typically use FOV scans to test whether AATS auto-tracking keeps the Sun centered in the AATS FOV, and to measure the FOV width and the slope of detector output vs pointing angle in the scan's central portion. (This slope determines the impact of tracking errors on AATS transmission measurements.) The bottom frame of Fig. A1 shows a frost-free scan made during the DC- 8 flight of 24 January 2003. It has the appearance of the satisfactory FOV scans made during our mountain calibrations. That is, the central portion of each channel's trace is flat to within $2 \%$ per degree of tracking angle (i.e., azimuth position), and the autotracking position of each channel (between the tops of the straight sloping lines radiating from lower left and right
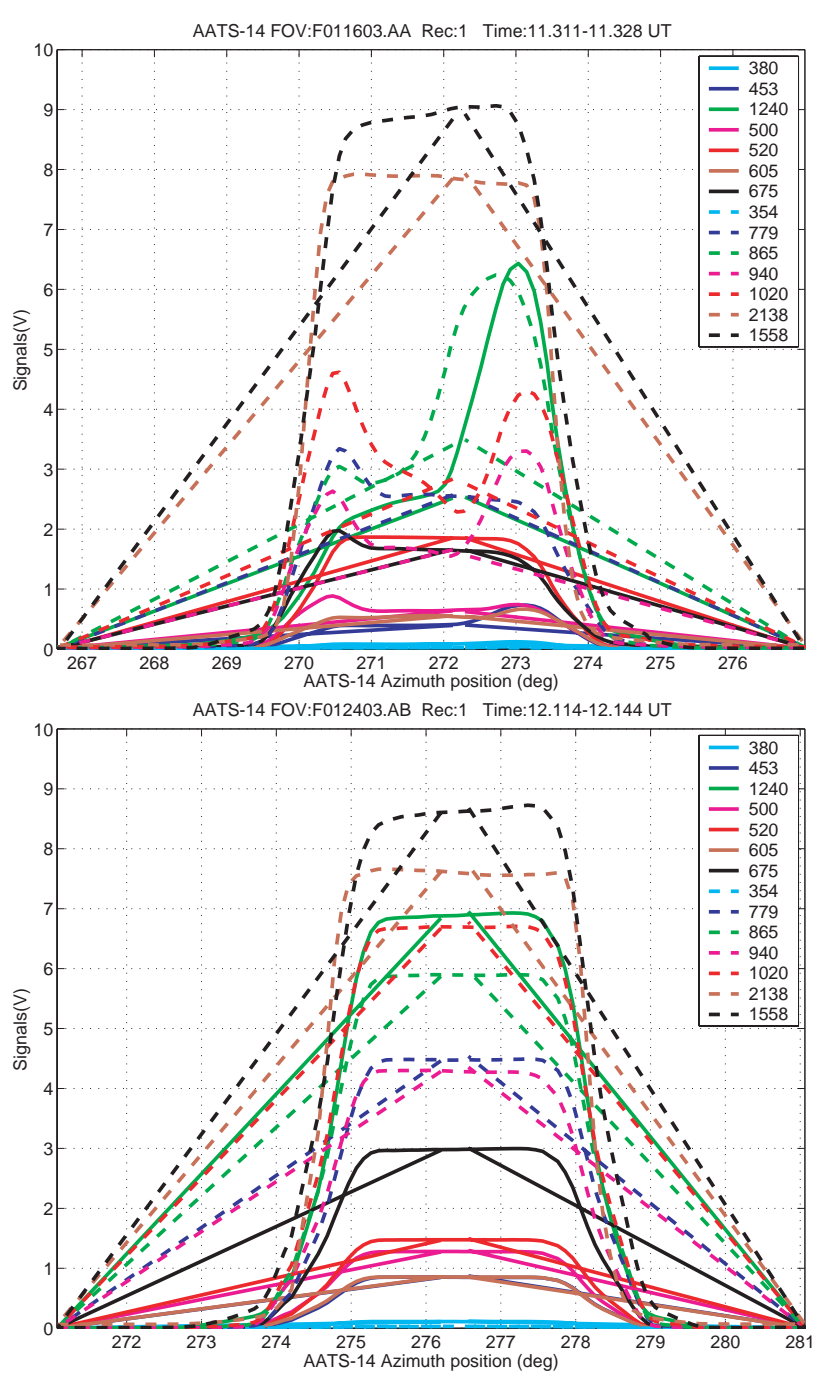

Fig. A1. AATS-14 field-of-view (FOV) scans. Top: Made during the DC-8 flight of 16 January 2003, showing the effect of window frost on all channels except 1558 and $2138 \mathrm{~nm}$. Bottom: Made during the DC-8 flight of 24 January 2003, showing the absence of window frost on all channels.

corners of the frame) is centered on the flat central part of the scan. From this appearance we judge the bottom frame to show a frost-free scan. The scans in the top frame contrast markedly, showing the effect of window frost on all channels except 1558 and $2138 \mathrm{~nm}$. Notice that the channels with frost have largest signal near a scan edge, with a local minimum toward the center. This behavior is consistent with the frost patch locations observed in the window photographs - i.e., toward the center of port entrances, away from the edges, which are heated by the foil.

FOV scans like those in Fig. A1 constituted one of four tests we made for window frost on the AATS flights in SOLVE II. We ran in-flight FOV scans and checked for the 
presence of "frost dips" like those shown in the top frame of Fig. A1. Each flight with $O D$ data shown in this paper had FOV scans free of "frost dips" and appeared like the bottom frame of Fig. A1.

A second frost test was to check the dependence of AATS derived $A O D$ on airmass. The presence of window frost on an AATS channel constitutes a change in that channel's calibration (from that determined in the pre- and post-mission mountain calibrations described by Livingston et al., 2005). Such a calibration change manifests itself as an $A O D$ error that is proportional to 1/airmass. To demonstrate this, we postulate a window coating with transmission $T_{\text {frost }}$. Then a given AATS channel's output $V$ is given by

$$
V=T_{\text {frost }} V_{0} \exp \left[-m_{a} O D_{a}-m_{R} O D_{R}-m_{g} O D_{g}\right],
$$

where $V_{0}$ is the top-of-atmosphere output determined in the mountain calibration, and subscripts $a, R$, and $g$ stand for aerosol, Rayleigh, and absorbing gases, respectively. Rearranging (A1) yields

$$
O D_{a}=-\left[\ln \left(V / V_{0}\right)+m_{R} O D_{R}+m_{g} O D_{g}-\ln T_{\text {frost }}\right] / m_{a}(\mathrm{~A} 2)
$$

or

$$
O D_{a}=O D_{a, t r u e}-\ln T_{\text {frost }} / m_{a},
$$

where $O D_{a, \text { true }}$ is the $O D_{a}$ obtained in the frost-free case, which has $T_{\text {frost }}=1$.

Equation (A3) shows that we can test for the presence of window frost by assuming, e.g., that

$O D_{a, t r u e}=O D_{a, S A G E}$

and testing to see whether $O D_{a}-O D_{a, S A G E}$ has the postulated $1 / m_{a}$ dependence.

We performed this test for all the AATS-SAGE comparison cases shown in this paper. Figure A2 shows a typical result, for the comparison of 29 January 2003. $O D_{a, A A T S}-O D_{a, S A G E}$ for all wavelengths is plotted $\mathrm{vs}_{a}$. Curves give $-\ln T_{\text {frost }} / m_{a}$ for the range of postulated $T_{\text {frost }}$ values that label each curve on the right hand axis. Note that the $O D_{a, A A T S}-O D_{a, S A G E}$ points do not follow the postulated $1 / m_{a}$ dependence. In fact, rather than decreasing with $m_{a}$, they increase. We found this to be the case for all AATSSAGE comparisons. In other words, this second test indicated no window frost.

A third test for window frost was to check whether $O D_{a, A A T S}-O D_{a, S A G E}$ was correlated with atmospheric temperature outside the DC-8. Scatter plots of $O D_{a, A A T S}-O D_{a, S A G E}$ vs this temperature (not shown for brevity) revealed no such correlation.

A fourth test was to check the wavelength dependence of $O D_{a, A A T S}-O D_{a, S A G E}$, or of $O D_{a, A A T S}$ itself. In the early cases where frost was present (not shown), the wavelength dependence was very erratic, corresponding to the frost occurrence pattern shown in the top row of Fig. A1 - i.e.,

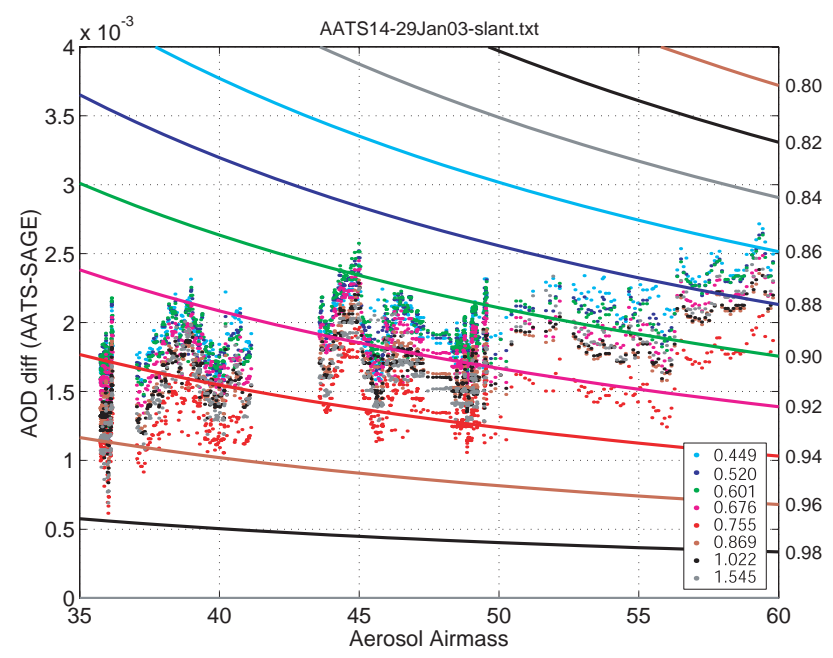

Fig. A2.Dependence of $A O D$ difference (AATS minus SAGE) on aerosol airmass, for 29 January 2003. Curves show airmass dependence that would be caused by a window deposit with transmission given by the numbers on the right-hand axis.

many channels affected by frost, but some channels unaffected. The wavelength dependence of these frost-affected $O D_{a}$ spectra could not be explained by any aerosol or PSC size distribution. In contrast, Figs. 8-13 and 15 show smooth spectra of $O D_{a, A A T S}$ and of $O D_{a, A A T S}-O D_{a, S A G E}$. Hence, this fourth test also indicates an absence of window frost.

To summarize, all four tests for window frost indicated that no frost was present for any of the cases with data presented in this paper. We thus conclude that the combined frost-prevention measures used in these cases - window heating and more extensive purging with dry nitrogen than for the early flights - were successful.

A related issue is whether anything could have deposited on other AATS optical surfaces and thereby decreased AATS channel transmissions. The optical path of each AATS channel has very few optical elements: the AATS entrance window, an interference filter, and a photodiode detector. Of these, the window was the coldest optical surface during the DC-8 flight segments reported in this paper. The detectors for wavelengths $354-1241 \mathrm{~nm}$ are in tight thermal contact with a mounting block maintained at an elevated temperature of $45 \pm 1 \mathrm{C}$, and the interference filters are in a mounting block with temperature that is continuously measured and found to stay within the range 30 to $42 \mathrm{C}$. Although the detector for wavelength $1558 \mathrm{~nm}$ has an internal chip thermoelectrically maintained at $0 \mathrm{C}$, its case and detector entrance window are warm, mounted in tight thermal contact with a block that is in conductive contact with the $45 \mathrm{C}$ hot-detector block and radiatively heated by the $30-40 \mathrm{C}$ filter block. Hence, the temperatures of all detector cases and filters greatly exceeded the AATS entrance window temperature during the DC- 8 flight segments reported in this paper. As a consequence, 
any material available to deposit on optical surfaces would deposit on the window, not a filter or detector (the only other optical elements). Moreover, if one were to postulate a deposit on an interference filter or detector, it would be revealed by the tests described in this Appendix, especially the plot of $A O D$ difference vs airmass shown in Fig. A2. As noted, the measured dependence on airmass is just the opposite of what would be caused by a deposit on any surface in the instrument optical path.

Acknowledgements. This research was supported by the National Aeronautics and Space Administration through the Upper Atmosphere Research Program and the Solar Occultation Satellite Science Team. We appreciate very useful discussions with L. Thomason. We thank L. Lait, M. Schoeberl, and P. Newman for providing the maps used in Fig. 1.

Edited by: K. S. Carslaw

\section{References}

Bodhaine, B. A., Wood, N. B., Dutton, E. G., and Slusser, J. R.: On Rayleigh optical depth calculations, J. Atmos. Ocean. Tech., 16, 1854-1861, 1999.

Bucholtz, A.: Rayleigh-scattering calculations for the terrestrial atmosphere, Appl. Opt., 34, 2765-2773, 1995.

Clough, S. A. and Iacona, M. J.: Line-by-line calculations of atmospheric fluxes and cooling rates II: Application to carbon dioxide, ozone, methane, nitrous oxide, and the halocarbons, J. Geophys. Res., 100, 16 519-16535, 1995.

DeMajistre, R. and Yee, J.-H.: Atmospheric remote sensing using a combined extinctive and refractive stellar occultation technique: 2. Inversion method for extinction measurements, J. Geophys. Res., 107, doi:10.1029/2001JD000795, 2002.

Fahey, D. W., Gao, R. S., Carslaw, K. S., et al.: The detection of large $\mathrm{HNO}_{3}$-containing particles in the Arctic stratosphere, Science, 291, 1026-1031, 2001.

Fromm, M., Alfred, J., and Pitts, M.: A unified, long-term, highlatitude stratospheric aerosol and cloud database using SAM II, SAGE II, and POAM II/III data: Algorithm description, database definition, and climatology, J. Geophys. Res., 108, doi:10.1029/2002JD002772, 2003.

Harder, J. W., Brault, J. W., Johnston, P. V., and Mount, G. H.: Temperature dependent $\mathrm{NO}_{2}$ cross sections at high spectral resolution, J. Geophys. Res., 102, 3861-3879, 1997.

Kneizys, F. X., Abreu, L. W., Anderson, G. P., Chetwynd, J. H., Shettle, E. P., Berk, A., Bernstein, L. S., Robertson, D. C., Acharaya, P., Rothmann, L. S., Selby, J. E. A., Gallery, W. O., and Clough, S. A.: The MODTRAN 2/3 Report and LOWTRAN 7 Model, 11 Jan. 1996, Phillips Laboratory, Geophysics Directorate PL/GPOS, 29 Randolph Road, Hanscom AFB, MA 017313010, 1996.

Kurucz, R. L.: Astrophysical Applications of Powerful New Databases, in: Astron. Soc. Pac., edited by: Adelman, S. J., Wiese, W. L., ASP Conf. Ser. Vol. 78, San Francisco, 205, 1995.

Livingston, J., Schmid, B., Russell, P., Eilers, J., Kolyer, R., Redemann, J., Ramirez, S., Yee, J.-H., Trepte, C., Thomason, L., Pitts, M., Avery, M., Randall, C., Lumpe, J., Bevilacqua, R., Bittner,
M., Erbertseder, T., McPeters, R., Shetter, R., Kerr, J., and Lamb, K.: Retrieval of ozone column content from airborne Sun photometer measurements during SOLVE II: Comparison with coincident satellite and aircraft measurements, Atmos. Chem. Phys. Discuss., 5, 243-286, 2005,

SRef-ID: 1680-7375/acpd/2005-5-243.

McKinney, K. A., Wennberg, P. O., Dhanijala, S., et al.: Trajectory studies of large HNO3-containing particles in the Arctic: Evidence for the role of NAT, Geophys. Res. Lett., 31, L05110, doi:10.1029/2003GL018430, 2004.

NASA Langley Research Center, SAGE III algorithm theoretical basis document: Solar and lunar algorithm, Rep. LaRC 475-00108, Vers. 2.1, Hampton, VA, 2002. (Available at http://eospso. gsfc.nasa.gov.)

Northway, M. J., Gao, R. S., Popp, P. J., et al.: An analysis of large $\mathrm{HNO}_{3}$-containing particles sampled in the Arctic stratosphere during the winter of 1999/2000, J. Geophys. Res., 107(D20), 8289, doi:10.1029/2001JD001079, 2002.

Randall, C. E., Bevilacqua, R. M., Lumpe, J. D., and Hoppel, K. W.: Validation of POAM III aerosols: comparison to SAGE II and HALOE, J. Geophys. Res. 106 (D21), 27 525-27 536, 2001.

Rothman, L. S. and Schroeder, J.: Millenium HITRAN Compilation, 12th Arm Science Team Meeting Proceedings, St. Petersburg, Florida, April 8-12, 2002.

Rothman, L. S., Chance, K., Schroeder, J., and Goldman, A.: New Edition of HITRAN Database, 11th Arm Science Team Meeting Proceedings, Atlanta, Georgia, March 19-23, 2001.

Russell, P. B., Livingston, J. M., Dutton, E. G., Pueschel, R. F., Reagan, J. A., DeFoor, T. E., Box, M. A., Allen, D., Pilewskie, P., Herman, B. M., Kinne, S. A., and Hofmann, D. J.: Pinatubo and pre-Pinatubo optical-depth spectra: Mauna Loa measurements, comparisons, inferred particle size distributions, radiative effects, and relationship to lidar data, J. Geophys. Res., 98, 22 969-22 985, 1993.

Schmid, B., Thome, K. J., Demoulin, P., Peter, R., Matzler, C., and Sekler, J.: Comparison of modeled and empirical approaches for retrieving columnar water vapor from solar transmittance measurements in the $0.94-\mu \mathrm{m}$ region, J. Geophys. Res., 101, 93459358, 1996.

Schmid, B., Michalsky, J. J., Slater, D. W., Barnard, J. C., Hathore, R. N., Liljegren, J. C., Holben, B. N., Eck, T. F., Livingston, J. M., Russell, P. B., Ingold, T., and Slutsker, I.: Comparison of columnar water-vapor measurements from solar transmittance methods, Appl. Opt., 40, 1886-1896, 2001.

Shetter, R. E. and Müller, M.: Photolysis frequency measurements using actinic flux spectroradiometry during the PEM-Tropics mission: Instrumentation description and some results, J. Geophys. Res., 104, 5647-5661, 1999.

Swartz, W. H., Yee, J.-H., Shetter, R. E., Hall, S. R., Lefer, B. L., Livingston, J. M., Russell, P. B., Browell, E. V., and Avery, M. A.: Column ozone and aerosol optical properties retrieved from direct solar irradiance measurements during SOLVE II, Atmos. Chem. Phys., 5, 611-622, 2005,

\section{SRef-ID: 1680-7324/acp/2005-5-611}

Taha, G., Thomason, L. W., Trepte, C., and Chu, W. P.: Validation of SAGE III Data Products Version 3.0, Quadrennial Ozone Symposium, QOS, 1-8 September, 2004, Kos, Greece, Proceedings of QOS., 115-116, 2004. 
Thomason, L. W. and Taha, G.: SAGE III aerosol extinction measurements: Initial results, Geophys. Res. Lett., 30, 33 (1-4), 2003.

Thomason, L. W., Herman, B. M., and Reagan, J. A.: The effect of atmospheric attenuators with structured vertical distributions on air mass determinations and Langley plot analyses, J. Atmos. Sci., 40, 1851-1854, 1983.

Vervack Jr., R. J., Yee, J.-H., Carbary, J. F., and Morgan, F.: Atmospheric remote sensing using a combined extinctive and refractive stellar occultation technique: 3. Inversion method for refraction measurements, J. Geophys. Res., 107, doi:10.1029/2001JD000796, 2002.
Yee, J.-H., Vervack Jr., R. J., DeMajistre, R., Morgan, F., Carbary, J. F., Romick, G. J., Morrison, D., Lloyd, S. A., DeCola, P. L., Paxton, L. J., Anderson, D. E., Krishna Kumar, C., and Meng, C.-I.: Atmospheric remote sensing using a combined extinctive and refractive stellar occultation technique: 1 . Overview and proof-of-concept observations, J. Geophys. Res., 107, doi:10.1029/2001JD000794, 2002.

Yee, J.-H., Swartz, W. H., Shetter, R. E., Hall, S. R., Lefer, B. L., Randall, C. E., Bevilacqua, R. M., Lumpe, J., Pitts, M. C., Zawodny, J. M., Thomason, L. W., Russell, P. B., Livingston, J. M., and Schmid, B.: Column composition retrieved from direct solar irradiance measurements during SOLVE II, Quadrennial Ozone Symposium, Kos, Greece, May-June 2004. 